\title{
SELAMENTO APICAL PROPICIADO POR ALGUMAS TÉCNICAS OBTURADORAS EM CANAIS CURVOS, QUE SOFRERAM DESVIO APICAL DE INSTRUMENTAÇÃO (ZIP)
}

Dissertação apresentada à Faculdade de Odontologia de Bauru da Universidade de São Paulo, como parte dos requisitos para obtenção do título de Mestre em Odontologia, área de Endodontia.

(Edição Revisada)

BAURU

2002 


\section{SELAMENTO APICAL PROPICIADO POR ALGUMAS TÉCNICAS OBTURADORAS EM CANAIS CURVOS, QUE SOFRERAM DESVIO APICAL DE INSTRUMENTAÇÃO (ZIP)}

Dissertação apresentada à Faculdade de Odontologia de Bauru da Universidade de São Paulo, como parte dos requisitos para obtenção do título de Mestre em Odontologia, área de Endodontia.

Orientador: Prof. Dr. Ivaldo Gomes de Moraes

(Edição Revisada)

BAURU

2002 


\section{Schimpf, Sonia de Oliveira Santos}

Sc63se Selamento apical propiciado por algumas técnicas obturadoras em canais curvos, que sofreram desvio apical de instrumentação (ZIP)./ Sonia de Oliveira Santos Schimpf. - Bauru, 2002.

88 p.: il.;30 cm.

Dissertação. (mestrado) - Faculdade de Odontologia de Bauru. Universidade de São Paulo.

Orientador: Prof. Dr. Ivaldo Gomes de Moraes

Autorizo, exclusivamente para fins acadêmicos e científicos, a reprodução total ou parcial desta dissertação/tese, por processos fotocopiadores e outros meios eletrônicos.

Assinatura:

Comitê de Ética da FOB

N. ${ }^{\circ}$ Do Protocolo: Proc. № 15/2002

Data: $22 / 11 / 2002$ 


\section{SONIA DE OLIVEIRA SANTOS SCHIMPF}

Nascimento

Filiação

$1981-1985$

$1988-1989$

$1995-2002$

$2000-2002$

Associações

07/04/1962

Lins - S.P.

João de Oliveira Santos

Maria Pires dos Santos

Curso de Graduação, na Faculdade de Odontologia de Lins

Curso de Especialização em Endodontia na Faculdade de Odontologia de Bauru - USP

Professora de Endodontia e Clínica Integrada da Faculdade de Odontologia de Lins - UNIMEP

Curso de Pós-Graduação em Odontologia, área de Endodontia, nível de Mestrado, na Faculdade de Odontologia de Bauru - USP

CROSP - Conselho Regional de Odontologia de São Paulo APCD - Associação Paulista de Cirurgiões Dentistas 


\section{DEDICATÓRIA}

Dedico este trabalho

Aos meus pais JOÃo e MARIA

Pessoas maravilhosas, base sólida e alicerce de minha vida, que além do amor e de um lar feliz, sempre me encorajaram diante das dificuldades e contratempos da vida.

Amo vocês! 
Dedico ainda este trabalho

Ao ADEMIR, meu esposo, pelo estímulo, dedicação e amor e ao MATHEUS meu querido filho pelo sorriso inspirador, pela compreensão nas ausências.

Com vocês ao meu lado, tudo se torna mais fácil! 


\section{AGRADECIMENTOS}

\section{A DEUS}

Pelo dom precioso da vida.

Obrigada Pai por todos os que entraram na minha história e me ajudaram a crescer. Obrigado pelo dia de hoje.

Recebe, Senhor, o ofertório alegre de minha eterna gratidão 
Agradeço

Aos meus irmãos: DILMA, JOÃO, NEUSA, MÁRCIA e CIDINHA, que sempre me incentivaram a prosseguir e que mesmo distantes mantiveram-se sempre ao meu lado. À vocês, minha gratidão profunda, admiração e amor. 
Agradeço especialmente

Ao meu orientador e Mestre Prof. Dr. IVALDO GOMES DE MORAES pela amizade, conselhos, paciência, incentivo, consideração, confiança e tranqüilidade na orientação deste trabalho. Admiro-te profundamente.

"Não basta ensinar ao homem uma especialidade porque se tornará uma máquina utilizável, mas não uma personalidade. É necessário que adquira um senso prático daquilo que vale a pena ser empreendido, do que é moralmente correto".

Albert Einstein, 1953 
Ao professor e amigo MITSURU OGATA, por estar sempre presente, pelo incentivo, apoio e confiança. Além de grande mestre, exemplo de Ser humano. Agradeço também àsua esposa Suelly.

"O amigo fiel é forte proteção; quem o encontrou, achou um tesouro"

Eclesiástico 
À Faculdade de Odontologia de Bauru (FOB), na pessoa da Diretora Prof. Dra. MARIA FIDELA DE LIMA NAVARRO.

À comissão de Pós-Graduação da FOB

Aos funcionários da Seção de Pós-Graduação da FOB, em especial ao AURÉLIO e GIANE, pela atenção.

Aos colegas do curso de Pós-Graduação, GUILHERME, GRAZIELA, JOSÉ FRANCISCO, JUAN, SILVANA, ULISSES, VICTOR HUGO e VIVIANE, que souberam ser verdadeiros irmãos, nos momentos difíceis.

Aos professores da disciplina de Endodontia da FOB, CLÓVIS MONTEIRO BRAMANTE, NORBERTI BERNARDINELI, IVALDO GOMES DE MORAES, ROBERTO BRANDÃO GARCIA e ALCEU BERBERT, pelo convívio, acolhida, disponibilidade, apoio e amizade.

Aos funcionários da disciplina de Endodontia, SUELY, D. NEIDE, EDIMAURO, PATRÍCIA E CLEIDE pelo carinho, atenção e eficiência. 
A TELMA LOPES DA SILVA da disciplina de Bioquímica da FOB pela disponibilidade.

Ao Prof. Dr. CARLOS WAGNER DE ARAÚJO WERNER pelo incentivo e versão do "Abstract".

Aos professores da disciplina de Endodontia da Faculdade de Odontologia de Lins, ANA PAULA, OGATA, FÁBIO e ASSIS, fiéis companheiros e grandes incentivadores.

Aos funcionários da Biblioteca da FOB, ADEMIR, CÉSAR, CYBELI, RITA, VALÉRIA e VERA, pela atenção, acolhida e presteza.

A VALÉRIA pela correção bibliográfica desta Dissertação.

Aos funcionários da Faculdade de Odontologia de Lins, em especial à SONIA, SOLANGE, LURDINHA, MARQUINHO, GILMAR e SIDNEY pela amizade, carinho e paciência. 


\section{AGRADECIMENTOS}

Aos funcionários do xerox da FOB, SALVADOR e MARQUINHOS pelo apoio e colaboração.

Ao Professor Dr. JOSÉ PEREIRA LAURIS pela atenção e solicitude na elaboração da análise estatística.

E a todos que, direta ou indiretamente colaboraram na realização deste trabalho.

Muito Obrigada! 


\section{LISTA DE TABELAS}

Tabela 1 - Infiltrações apicais (em $\mathrm{mm}$ ) de Rhodamine B a $0,2 \%$ medidas nas obturações realizadas com Cimento OZE. .52

Tabela 2 - Infiltrações apicais (em $\mathrm{mm}$ ) de Rhodamine B a 0,2\% medidas nas obturações realizadas com Cimento AH Plus acrescido de 5\% de hidróxido de cálcio. .52

Tabela 3 - Médias e desvios padrão das infiltrações medidas nas oitenta obturações realizadas .53

Tabela 4 - Análise da Variância a 2 critérios demonstrando o efeito dos cimentos e das técnicas e também a interação entre ambos. .53

Tabela 5 - Teste de Tukey para comparações demonstrando diferença estatisticamente significante favorável a técnica do System B em relação a Moldagem Térmica de cone principal e técnica do Thermafil. .53 


\section{LISTA DE FIGURAS}

Figura 1 - A - Base de resina acrílica para posicionamento das raízes sempre na mesma posição nas tomadas radiográficas. B - Raiz mésio-vestibular com a lima do tipo Kerr n.․ 15 ajustada no canal, para auxiliar a confecção do leito necessário àsua reposição. .38

Figura 2 - Dispositivo utilizado nas tomadas radiográficas para verificação da formação do "ZIP". .38

Figura 3 - Raiz posicionada na base de acrílico com uma lima do tipo Kerr n.․ 15 no momento da odontometria 39

Figura 4 - Imagens radiográficas demonstrando a formação do "ZIP" de instrumentação. A - antes (lima n.ำ 15). B - após (lima n.ํㅜ 30) .40

Figura 5 - Desenhos do contorno das raízes com lima do tipo Kerr n. -15 (preto) e n. .30 (vermelho), posicionadas no canal radicular. A diferença de posicionamento das extremidades das limas caracterizou o desvio apical de instrumentação.

Figura 6 - cimento de óxido de zinco e Eugenol. .43

Figura 7 - cimento AH Plus .44 
Figura 8 - Hemissecções com canais obturados pela técnica do System B. A - AH Plus com $5 \%$ de hidróxido de cálcio. B - OZE...... 48

Figura 9 - Hemissecções com canais obturados pela técnica da Condensação Lateral. A - AH Plus com $5 \%$ de hidróxido de cálcio. B - OZE. .49

Figura 10 - Hemissecções com canais obturados pela técnica do Thermafil. A AH Plus com $5 \%$ de hidróxido de cálcio.B - OZE... .49

Figura 11 - Hemissecções com canais obturados pela Técnica da Condensação Lateral com Moldagem Térmica do Cone principal. A - AH Plus com $5 \%$ de hidróxido de cálcio. B - OZE...... .50

Figuras 12 e 13 - Gráficos representativos das médias de infiltração permitidas pelas obturações em função dos cimentos e técnicas estudadas. .54 


\section{SUMÁRIO}

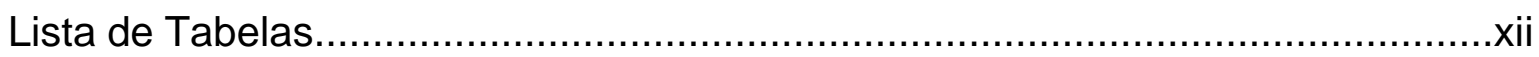

Lista de figuras................................................................................

Lista de Abreviaturas e Símbolos.......................................................xvii

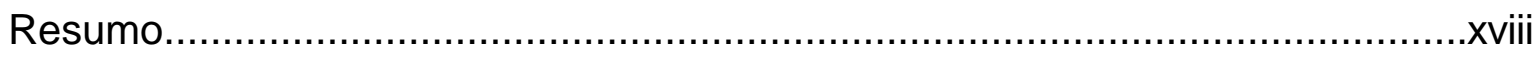

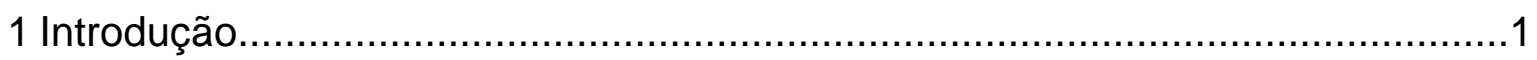

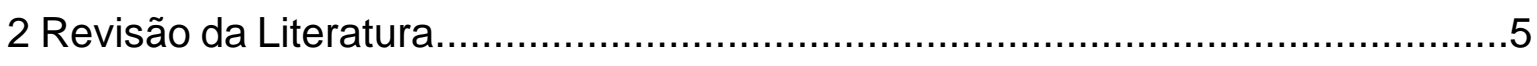

2.1 Selamento apical em função das Técnicas Obturadoras..............................6

2.2 Selamento Apical em função dos Cimentos Obturadores............................20

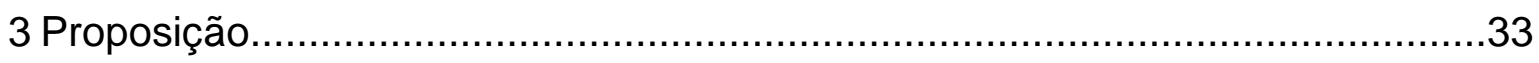

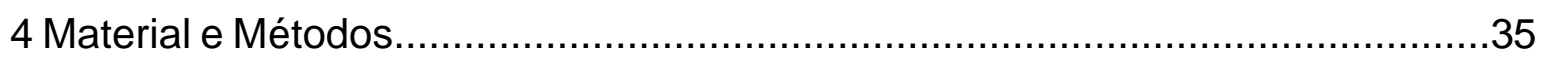

4.1 Seqüência do preparo biomecânico dos Canais Radiculares.......................36

4.2 Impermeabilização das superfícies externas das raízes.............................42

4.3 Divisão dos elementos radiculares em função dos cimentos e das técnicas de obturação preconizados. 


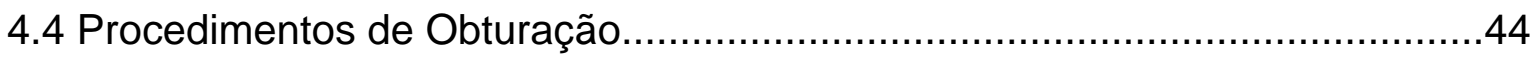

4.5 Obturação dos canais das raízes dos grupos G1-1 e G2-1 .........................45

4.6 Obturação dos canais das raízes dos grupos G2-1 e G2-2 .......................46

4.7 Obturação dos canais das raízes dos grupos G1-3 e G2-3......................46

4.8 Obturação dos canais das raízes dos grupos G1-4 e G2-4......................47

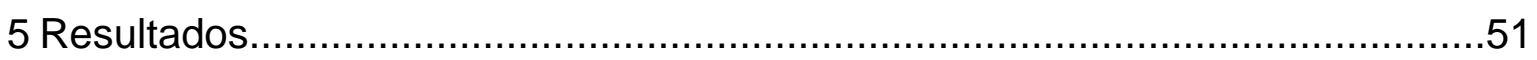

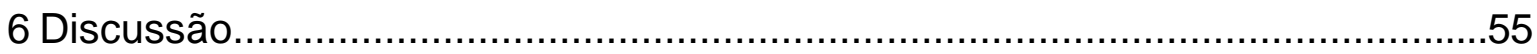

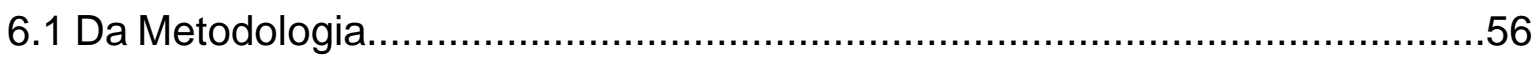

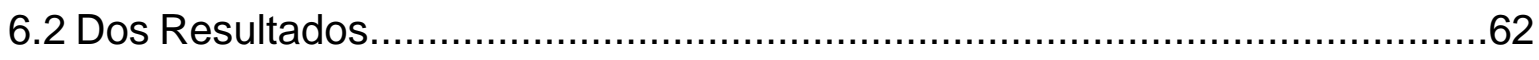

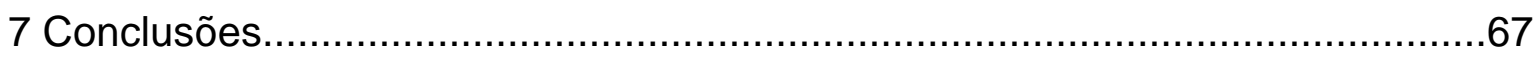

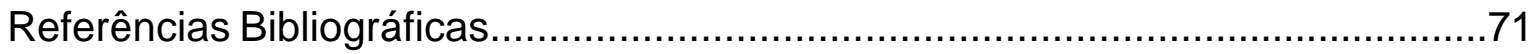

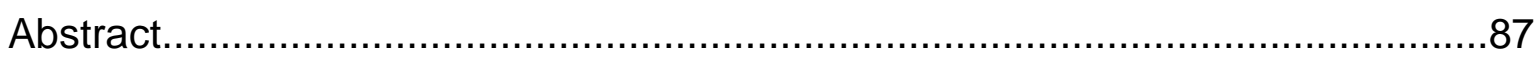

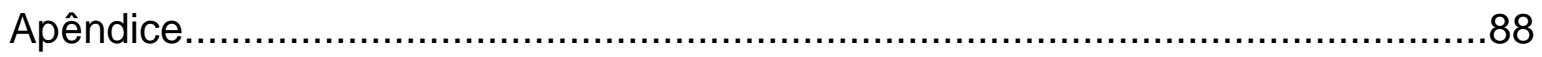




\section{LISTA DE ABREVIATURAS E SÍMBOLOS}

\begin{tabular}{|c|c|}
\hline$\%$ & Porcentagem \\
\hline$X$ & Vezes \\
\hline G & Grupo \\
\hline G & Grama \\
\hline $\mathrm{Cm}$ & Centímetro \\
\hline $\mathrm{Mm}$ & Milímetro \\
\hline Ml & Mililitro \\
\hline $\mathrm{Dp}$ & Desvio-padrão \\
\hline $\mathrm{H}$ & Hora \\
\hline $\mathrm{n} . \stackrel{0}{-}$ & Número \\
\hline OZE & Óxido de Zinco e Eugenol \\
\hline$P$ & Significância estatística \\
\hline IRM & Material Restaurador intermediário \\
\hline Ltda & Limitada \\
\hline $\mathrm{pH}$ & Potencial hidrogênico \\
\hline 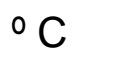 & Graus Celsius \\
\hline EDTA & Ácido etileno diamino tetracético \\
\hline EUA & Estados Unidos da América \\
\hline FOB & Faculdade de Odontologia de Bauru \\
\hline USP & Universidade de São Paulo \\
\hline NS & Não significante \\
\hline Kv & Kilovoltagem \\
\hline
\end{tabular}




\section{RESUMO}

Avaliou-se "in vitro" o selamento apical em canais curvos que sofreram desvio apical de instrumentação (ZIP), utilizando quatro técnicas obturadoras: Condensação Lateral, Condensação Lateral com moldagem térmica direta do cone principal, Thermafil e System B e dois tipos de cimentos: Óxido de zinco e eugenol e AH Plus acrescido de 5\% de Hidróxido de Cálcio. Foram empregadas 80 raízes mésio-vestibulares de dentes molares superiores humanos extraídos. Foi realizada a instrumentação pela Técnica Escalonada Regressiva, tendo como instrumento memória a lima do tipo Kerr $n . \stackrel{\circ}{30}$, realizando-se o recuo até a $n$. ㄴ 45. As raízes tiveram suas superfícies externas impermeabilizadas e os canais foram obturados segundo as técnicas citadas. Imediatamente após a obturação, as raízes foram impermeabilizadas no terço cervical com cera rosa derretida e imersas em solução corante de Rhodamine B a 0,2\% por 72 horas a 37ํㅡ. Para avaliação da infiltração as raízes foram desgastadas no sentido longitudinal em uma das faces proximais até expor-se a obturação. As infiltrações foram medidas com auxilio de uma ocular micrometrada pela técnica linear da planimetria em microscópio óptico comum. Após análise estatística constatou-se que a Técnica do System B, bem como, o cimento AH plus acrescido de $5 \%$ de hidróxido de Cálcio apresentaram melhores resultados quando comparados \$̀ demais técnicas estudadas e ao cimento de Óxido de Zinco e Eugenol. 


\section{INTRODUÇÃO}

O desvio apical de instrumentação, durante o preparo biomecânico de canais curvos, constitui-se em um sério problema, pois a deformação do canal numa região tão crítica como a apical, provocará dificuldades no selamento do canal, fato este, que está diretamente relacionado ao sucesso do tratamento endodôntico.

Em 1956, INGLE ${ }^{53}$, descreveu sobre a importância de se obturar os canais radiculares da forma mais hermética possível, relacionando os fracassos endodônticos com obturações insatisfatórias.

Em 1975, WEINE; KELLY; LIO ${ }^{89}$, alertaram para a deformação que pode ocorrer no forame apical durante a instrumentação. Foram confeccionados blocos de resina com canais curvos e diâmetros conhecidos, sendo instrumentados por 10 clínicos, que utilizaram várias técnicas, normalmente usadas de rotina. Observaram que nenhum dos preparos tinha a forma cônica e que a porção mais estreita do preparo não estava no ápice, mas na porção média da curvatura, resultando numa forma de ampulheta. A porção mais estreita foi denominada cotovelo do preparo. As limas pré-curvadas, quando inseridas nos canais curvos, tendem a se tornar retas, determinando um desgaste em forma de gota, denominada ZIP.

Muitas técnicas de instrumentação manuais e mecânicas foram idealizadas com a finalidade de evitar tal iatrogenia, sem, contudo, lograrem efeito em $100 \%$ dos casos, bem como várias técnicas obturadoras, sempre na tentativa de obliterar hermeticamente o sistema de canais radiculares, selando 
imperfeições criadas ou não pelo profissional, como por exemplo o ZIP.

INGLE; TAINTOR ${ }^{54}$, em 1985, afirmaram que $63,46 \%$ dos insucessos endodônticos, são resultantes de obturações permeáveis e insatisfatórias, enquanto que ALLEN $^{4}$, em 1964, atribui mais de $90 \%$ dos fracassos a selamentos incompletos. LEONARDO; LEAL $^{64}$, em 1998, estudando diversos autores, obtiveram uma média total de sucesso para biopulpectomia de 92,86\%; para necropulpectomia I, de $86,64 \%$ e para necropulpectomia II, de 70,35\%. Citaram o limite apical de obturação como fator influente na reparação apical e periapical.

WU; BING FAN; WESSELINK ${ }^{93}$, em 2000 avaliaram o selamento apical em canais curvos que sofreram desvio apical de instrumentação. Na $1^{\underline{a}}$ parte do estudo eles compararam duas técnicas de instrumentação: Lightspeed e a manual escalonada regressiva. Concluíram que na técnica manual, $87 \%$ dos canais sofreram desvios e perfurações e com Lightspeed tal iatrogenia ocorreu em $19 \%$ do casos. Todos os dentes foram obturados com cimentos AH 26 pela Técnica de Condensação Lateral e a avaliação do selamento apical se fez com o uso do dispositivo de transporte de fluido. Os resultados comprovaram que a ocorrência do desvio apical é um fator que influencia negativamente o selamento apical em canais curvos obturados pela Técnica da Condensação Lateral.

Diante do exposto percebe-se a grande necessidade de se utilizar uma técnica de obturação, bem como um cimento obturador que proporcionem um selamento hermético da porção mais apical do canal radicular, o que é bastante crítico visto que essa porção torna-se deformada quando ocorre o desvio de instrumentação (ZIP). 
$\mathrm{Na}$ literatura, poucos são os trabalhos conclusivos a respeito do comportamento e efetividade de materiais e técnicas obturadoras para selamento do ZIP, e diante desse quadro, torna-se necessário um estudo para esclarecer qual tipo de cimento e qual técnica obturadora apresentam melhores resultados. 


\section{REVISÃO DE LITERATURA}

Para facilitar a leitura, a revisão de literatura será abordada seguindo os tópicos:

Selamento apical em função:

2.1 das Técnicas Obturadoras

2.2 dos Cimentos Obturadores

\subsection{SELAMENTO APICAL EM FUNÇÃO DAS TÉCNICAS OBTURADORAS}

BRAMANTE et al. $^{21}$, em 1989, avaliaram obturações de canais radiculares realizadas pelas técnicas de Condensação Lateral com limas tipo Kerr, Finger Spreader e pontas de Rhein; técnica de Schilder, Mc Spadden, Híbrida de Tagger e sistema Ultrafil. Setenta dentes caninos humanos recém extraídos foram divididos em sete grupos de 10 dentes, e os canais foram instrumentados a $1 \mathrm{~mm}$ além do forame apical até a lima do tipo Kerr $\mathrm{n} . \stackrel{0}{35}$. A confecção do batente apical foi feita a $1 \mathrm{~mm}$ aquém do forame apical até a lima do tipo Kerr $n .{ }^{\circ} 50$, realizando-se o escalonamento regressivo até a lima do tipo Kerr n.80. A irrigação foi realizada com soro fisiológico, seguida por EDTA. Os espécimes foram impermeabilizados com Araldite e esmalte para unhas, exceto nas proximidades do ápice e os canais obturados com as técnicas citadas. O cimento utilizado foi o de Óxido de Zinco e Eugenol, que foi levado ao canal através do cone principal, sem ocupar sua extremidade. Concluída as obturações 
os dentes foram imersos em corante solução azul de metileno a $2 \%$ por 7 dias a $37^{\circ} \mathrm{C}$. Transcorrido o período, os espécimes foram seccionados longitudinalmente para análise da infiltração. As técnicas que apresentaram melhor desempenho foram da Condensação Lateral com limas do tipo Kerr e Híbrida de Tagger. A Técnica do Sistema Ultrafil apresentou uma acentuada infiltração marginal e características de deficiência da obturação.

BAUMGARDNER; KRELL ${ }^{11}$, em 1990 compararam a Condensação Lateral da guta-percha com e sem ativação ultra-sônica do espaçador através da penetração de corante e fotos das obturações realizadas pelo microscópio eletrônico de varredura. Os dentes foram divididos em 3 grupos de 10 e tiveram os canais obturados pela técnica da Condensação Lateral, com espaçador ativado com ultra-som, com espaçador digital fino ou com o espaçador do ultrasom sem ser ativado. O cimento utilizado foi o Roth's 801 (Roth's). O ultra-som foi o ENAC (Osada Eletric Co, LTDA., Osaka, Japão) ligado na potência 3. A Técnica instrumental foi a escalonada regressiva tendo como instrumento memória a lima de número 35 e a solução irrigadora foi a solução de hipoclorito de sódio a 2,5\%. Os autores esclareceram que a ponta energizada do ultra-som não foi utilizada para promover aquecimento e termoplastificar a guta-percha. A ponta foi introduzida manualmente até encontrar resistência e ativada com uma leve pressão apical que penetrasse no comprimento real de trabalho. Terminada as obturações, os dentes foram colocados em umidade de $100 \%$ a $38^{\circ} \mathrm{C}$ por 48 horas. As raízes foram impermeabilizadas com cera, exceto nos 2 a $3 \mathrm{~mm}$ apicais e inseridas no corante Pelikan por dez dias. Após esse período, foram lavadas em água, descalcificadas com ácido nítrico a 5\% e clareadas com metil salicilato. A 
análise da infiltração foi feita pelo uso de um microscópio com aumento de 7X e aproximação de $0,1 \mathrm{~mm}$. Como resultado observaram que ocorreu uma infiltração significantemente menor do corante nos dentes que foram obturados usando espaçador ativado com ultra-som. A correlação entre a massa de guta-percha e a infiltração apical foi observada. A massa de guta-percha obtida com a condensação com o ultra-som foi mais homogênea, com poucas falhas, quando comparadas com os outros dois grupos.

LARES; ELDEEB ${ }^{61}$, em 1990, avaliaram através de infiltração de corante, a capacidade de selamento apical das técnicas Thermafil e Condensação Lateral ativa. Quarenta caninos superiores com canais retos e quarenta canais curvos de vinte raízes mesiais de molares inferiores foram utilizados. Os dentes foram instrumentados $2 \mathrm{~mm}$ além do forame apical com uma lima Kerr de nํ 15 e o comprimento real de trabalho ficou de 0,5 a $1 \mathrm{~mm}$ aquém de comprimento real do dente, sendo que os canais retos foram instrumentados até a lima Kerr de no 55 e os curvos até a tipo Kerr de no 30 . A solução irrigadora foi o hipoclorito de sódio a 1\%. A porção apical dos canais foi instrumentada com técnica step-back e a porção cervical com brocas de Gates Glidden 2 e 3. Os espécimes foram divididos em dois grupos de quarenta dentes cada sendo que o grupo experimental foi obturado pela Técnica Thermafil e o grupo controle pela técnica de Condensação Lateral. Como resultado observaram que nos canais retos, a infiltração de corante foi menor na técnica da Condensação Lateral ativa, quando comparada ao Thermafil. Já nos canais com curvatura, a diferença não foi estatisticamente significante.

HATA et al. ${ }^{47}$, em 1992, estudaram o selamento apical de canais 
radiculares obturados pelas técnicas: Thermafil com cimento de oxido de Zinco e Eugenol, Thermafil sem cimento e Condensação Lateral. Foram utilizadas duas técnicas de instrumentação: preparo convencional step-back com limas K-Flex e a instrumentação tradicional, combinando alargadores e limas K-Flex. Assim, quarenta e oito primeiros molares superiores humanos foram utilizados, divididos em dois grupos experimentais com 24 dentes cada de acordo com as duas técnicas de instrumentação. Na seqüência, cada grupo foi dividido em 3 subgrupos de 8 elementos, de acordo com as diferentes técnicas obturadoras. Cada dente tinha 3 canais, totalizando 24 canais para técnica de obturação. Terminada as obturações, os espécimes foram preparados para a avaliação do selamento, usando corante Pelikan e um Perfilômetro. A extensão da penetração do corante foi avaliada estatisticamente para cada um dos três canais, com uma analise de variância. Os autores concluíram que não houve diferença significante para a capacidade de selamento entre o preparo convencional step-back e a técnica de instrumentação convencional, porém, houve diferença significante entre as técnicas de obturação. A média linear de penetração de corante foi maior para a Técnica do Thermafil do que para a Condensação Lateral.

GENÇOGLU; SAMANI; GUNDAY $^{41}$, em 1993, estudaram a adaptação da guta-percha termoplastificada ̀̀ paredes dos canais na ausência e presença de "smear layer", quando da utilização das técnicas de obturação do Thermafil e Ultrafil, comparando-as com a técnica da Condensação Lateral. Sessenta e quatro dentes unirradiculados humanos extraídos tiveram os canais instrumentados pela técnica step-back com um batente confeccionado com diâmetro de um instrumento 60 e brocas Gates-Glidden para dilatação do terço 
cervical. Os dentes foram divididos em 2 grupos sendo que em um deles, a "smear layer" foi removida (EDTA 17\%) e no outro, não. Os dentes de cada grupo foram subdivididos em 3 subgrupos, e os canais foram obturados com as técnicas de Condensação Lateral, Ultrafil e Thermafil, utilizando cimento de Grossman. Foram utilizados dois grupos controle, com 2 dentes de cada grupo cujos canais não foram obturados, dois continham "smear layer" e os outros não. Pela análise com o microscópio eletrônico de varredura, verificaram que ambos os sistemas de termoplastificação da guta-percha mostraram melhor adaptação nas paredes do canal radicular na presença ou ausência de "smear layer". Na ausência de "smear layer", a adaptação foi melhor em todos os grupos. Quando o cimento foi utilizado e a "smear layer" foi removida, observaram um aumento na capacidade da gutapercha termoplastificada em penetrar no interior dos túbulos dentinários.

DALAT; SPANGBERG ${ }^{30}$, em 1994, avaliaram a infiltração apical em canais radiculares obturados com as técnicas do Cone único, Condensação Lateral, Condensação Vertical, Thermafil e Ultrafil. Setenta e nove dentes superiores anteriores tiveram suas coroas removidas e os canais instrumentados pela técnica step-back até a lima do tipo Kerr $\mathrm{n}^{\circ}$ 45, $1 \mathrm{~mm}$ aquém do ápice radicular. Os espécimes foram divididos em 5 grupos de quinze dentes cada, dois grupos para controle positivo e dois grupos para controle negativo. O cimento obturador foi o $\mathrm{AH} 26$. Após as obturações, os dentes foram imersos em solução de azul de metileno a $2 \%$, em vácuo. Posteriormente, os dentes foram seccionados longitudinalmente e medida a penetração linear de corante. Os autores concluíram que não houve diferenças significantes entre os métodos de obturação com relação àpenetr ação de corante. 
SANTA CECÍLIA ${ }^{77}$, em 1994, avaliou a capacidade de selamento apical da técnica Thermafil, comparando a técnica da Condensação lateral, bem como a influência da forma, direção absoluta e calibre dos canais no selamento apical. Utilizou 82 raízes de molares humanos extraídos divididas em 2 grupos:

Grupo 1 = canais curvos e atrésicos

Grupo 2 = canais retos e amplos

O cimento obturador utilizado para todos os grupos foi o Endofill. Concluiu que quanto ao selamento apical, não foram detectadas diferenças estatisticamente significantes entre as técnicas da Condensação Lateral e Thermafil e que a microinfiltração nos canais curvos e atrésicos foi maior que nos amplos e retos, com diferença estatisticamente significante $(p<0,05)$.

ANIC; MATSUMOTO ${ }^{8}$, em 1995, analisaram quatro técnicas diferentes para obturação de canais radiculares: Condensação Lateral, Ultrafil, Condensação Vertical com guta-percha amolecida por meio de 3 diferentes tipos de laser: Argon, $\mathrm{CO}_{2}$ e $\mathrm{Nd}$ :YAG ou resina composta fotopolimerizada pelo laser Argon. Para análise do selamento apical, setenta raízes de dentes humanos extraídos unirradiculados tiveram os canais instrumentados pela técnica step-back e obturados com as técnicas citadas. Terminadas as obturações, os dentes foram imersos em solução corante de azul de metileno a $1 \%$ a $37^{\circ} \mathrm{C}$ por, 7 dias. Os autores observaram que os canais obturados com resina composta sofreram maior penetração, seguido pela guta-percha aquecida pelos laser $\mathrm{CO}_{2}$ e $\mathrm{Nd}$ :YAG. A guta-percha plastificada pelo laser Argon propiciou um selamento idêntico ao obtido pela Condensação Lateral e Ultrafil. Concluíram que o laser Argon pode ser usado para a plastificação da guta-percha e produzir bons resultados quanto 
ao selamento apical.

GOLDBERG; MASSONE; ARTAZA ${ }^{43}$, em 1995, avaliaram o selamento apical proporcionado pelas técnicas de obturação Trifecta, Condensação Lateral e uma combinação da guta-percha Successfil e Condensação Lateral. Quarenta e sete incisivos centrais superiores com raízes retas tiveram os canais instrumentados usando-se brocas de Gates Glidden 1,2 e 3 nos terços cervical e médio e o instrumento memória foi àima do tipo Kerr nำ 45, $1 \mathrm{~mm}$ aquém do ápice radicular. A solução irrigadora utilizada foi o Hipoclorito de Sódio a 2,5\%. Os dentes foram divididos em três grupos de 14 e um grupo adicional, de cinco dentes que não tiveram os canais obturados e serviram de controle positivo. Terminadas as obturações, os dentes foram radiografados no sentido vestíbulo-lingual e mésio-distal para análise da qualidade da obturação e imersos em corante Pelikan. O comprimento máximo de penetração foi medido usando um microscópio óptico. Não houve diferença estatisticamente significante entre os grupos.

HATA et al. ${ }^{48}$, em 1995, estudaram o selamento apical dos canais radiculares através da infiltração de uma resina, a resorcinol formaldeído, nos espaços vazios da obturação. Foram instrumentados cento e cinqüenta dentes unirradiculados e divididos em diferentes grupos, de acordo com a técnica de obturação: Thermafil, Obtura II, Ultrafil "Firm set” e Ultrafil "regular set”, utilizando ou não cimento endodôntico. A Técnica da Condensação Lateral, associada ao cimento obturador foi utilizada como grupo controle. Concluída a etapa da obturação, os dentes foram mantidos em temperatura ambiente durante 2 dias e impermeabilizados. Após este período foram imersos em resina por cinco dias a 
$4^{\circ} \mathrm{C}$ e para que a polimerização da resina se completasse permaneceram por quatro dias em temperatura ambiente.

Os dentes foram seccionados transversalmente a 1,5, 2,5 e 3 milímetros aquém do ápice e examinados e fotografados em um estereomicroscópio. Concluíram que não houve diferença estatisticamente significante na infiltração apical medida no mesmo nível para diferentes materiais obturadores. Entretanto a infiltração foi significante menor para todos os materiais quando a técnica estava associada ao cimento.

PATHOMVANICH; EDMUNDS ${ }^{74}, 1996$, avaliaram in vitro,a penetração apical de corante em obturações feitas com Thermafil e Condensação Lateral. Cento e vinte dentes humanos extraídos foram analisados sob condições de centrifugação, penetração passiva de corante, uma técnica a vácuo e uma técnica de aumento de pressão de ar. Uma lima flexofile n.․1 foi introduzida no canal radicular além do forame e o batente apical foi feito a $1 \mathrm{~mm}$ aquém do comprimento real do dente. Para dilatar a parte reta do canal foi utilizada uma broca de Gates Glidden e o instrumento memória de número 3 vezes acima do diâmetro anatômico do canal. A solução irrigadora foi o Hipoclorito de Sódio a 1\%. Os dentes foram divididos em 8 grupos: 4 obturados com Thermafil e 4 pela Técnica de Condensação Lateral. A infiltração foi medida expondo um grupo de amostra de cada Técnica de obturação para cada um dos quatro sistemas de penetração do corante Pelikan. Após os dentes serem desmineralizados e clareados, foi registrada a penetração máxima de corante para cada amostra. Não houve diferença estatística entre as quatro técnicas de infiltração e entre as duas técnicas de obturação. 
WU; GEE; WESSELINK ${ }^{91}$, em 1997, estudaram a infiltração dos cimentos AH26 e Ketac-Endo quando utilizados com guta-percha aquecida e injetada. Cento e quatro raízes foram utilizadas e para determinar a infiltração, um dispositivo de transporte de fluído. A guta-percha aquecida teve por finalidade, reduzir a distância entre a parede do canal radicular e a guta-percha, permitindo uma camada menos espessa do cimento obturador. Após a condensação, a distância entre a guta-percha e a parede do canal foi menor que $25 \mu \mathrm{m}$. O cimento AH26 com um filme de espessura de $39 \mu \mathrm{m}$ infiltrou mais que o cimento KetacEndo que apresentou um filme com espessura de $22 \mu \mathrm{m}$. Os autores observaram que a espessura do filme de cimento é um fator que influência na capacidade de selamento das obturações quando a condensação da guta-percha termoplastificada é realizada.

LEE; VAN CURA; BEGOLE ${ }^{63}$, em 1998, estudaram a temperatura na superfície radicular produzida durante a condensação vertical aquecida empregando os aparelhos System B, o Touch'n Heat e um carregador aquecido na chama. Trinta canais de dentes incisivos superiores, pré-molares e incisivos inferiores foram divididos em 3 grupos e obturados empregando as técnicas citadas. Um dispositivo foi colocado $2 \mathrm{~mm}$ abaixo da união cemento-esmalte para transferir a temperatura da superfície externa da raiz para um termômetro digital. Para o System B, a temperatura foi menor que $10^{\circ} \mathrm{C}$ para todos os dentes avaliados. Para o Touch'n Heat, a temperatura foi inferior a $10^{\circ} \mathrm{C}$ para os dentes incisivos superiores e pré-molares e superior a $10^{\circ} \mathrm{C}$ nos incisivos inferiores. Os carregadores aquecidos na chama, apresentaram temperatura superior à $10^{\circ} \mathrm{C}$ em todos os dentes avaliados. O nível crítico de calor requerido para produzir 
danos ósseos irreversíveis deve ser acima de $10^{\circ} \mathrm{C}$. Neste estudo, os dados sugerem que o emprego do aparelho System B não promove danos aos tecidos perirradiculares que deve-se tomar cuidado com o uso do Touch'n Heat e carregadores aquecidos em chama, quando usados em incisivos inferiores.

SILVER; LOVE; PURTON ${ }^{80}$, em 1999, avaliaram duas técnicas de condensação vertical: System B e Touch'n Heat modificada. Neste estudo os autores compararam a área do canal ocupada por guta-percha, cimento ou lacunas. Secundariamente compararam as mudanças de temperatura na superfície externa das paredes dos canais radiculares durante a fase da obturação. Quarenta e cinco blocos de resina, cada um com um canal principal e cinco canais laterais padronizados foram divididos em três grupos iguais. Os canais foram obturados com o aparelho System B utilizando duas temperaturas diferentes para colocação e com condensação vertical com o aparelho Touch'n Heat com uma fonte de calor. Um modelo para transferência de temperatura foi usado simultaneamente para gravar as mudanças de temperatura interna e externa da superfície radicular durante a obturação. Ambas as técnicas produziram obturação radicular, consistindo acima de 90\% de guta-percha na maioria dos níveis. Através das porcentagens de cimento e lacunas de 2 a $3 \mathrm{~mm}$ do comprimento de trabalho, a Técnica do System B foi superior àCondensação vertical modificada. Esta última resultou em mais guta-percha nos canais laterais. A obturação foi realizada mais rapidamente com o aparelho System B. As elevações de temperatura durante 0 emprego do System B foram significantemente menores que a produzida pela condensação vertical modificada. Com o Touch'n Heat houve uma elevação de temperatura acima de 
10 C na superfície radicular externa. Como conclusão, os autores relatam que a Técnica de obturação com System B pode produzir uma obturação aceitável e que o uso do Touch'n Heat durante a condensação vertical pode causar danos periodontais.

HAÏ KEL et al. ${ }^{45}$, em 2000, estudaram a infiltração apical das técnicas de Condensação Lateral, Thermafil e Mc Spadden. Cento e noventa e dois dentes humanos extraídos unirradiculados, sem curvatura, foram preparados usando como instrumento memória uma lima do tipo Kerr n.ำ 30 e Gates Glidden na região média e cervical e obturados com as técnicas citadas. Os dentes foram impermeabilizados com esmalte, exceto a $1 \mathrm{~mm}$ do ápice e a avaliação quantitativa da infiltração apical foi obtida após os períodos de 1 dia, 7, 14 e 28 dias da imersão na solução marcadora de lisozima com iodo radioativo preparado por secções horizontais dos dentes medindo o nível de radioatividade em cada secção, usando um contador gama. No grupo do Thermafil a infiltração foi menor no 1. dia e foi significantemente diferente das técnicas. A infiltração foi maior nas amostras da Condensação Lateral. No final do estudo (28 dias), os valores para a Condensação Lateral foram menores, mas foram significantemente diferentes apenas do grupo Mc Spadden. Para todas as técnicas a infiltração foi mais significante nos primeiros $3 \mathrm{~mm}$ do ápice e foi muito menor após este nível, tanto que todos os métodos podem ser considerados como capazes de selar hermeticamente após 3mm do ápice.

SMITH et al. ${ }^{82}$, em 2000, estudaram a influência da profundidade da aplicação do calor na qualidade da obturação de canais radiculares obturados com o System B. Para tanto, um modelo de dente seccionado foi utilizado, onde 
foram confeccionadas irregularidades prévias à obturação. Os canais foram obturados com o condensador inserido a três, quatro, cinco e sete milímetros aquém do comprimento de trabalho, Concluíram que, quanto maior a profundidade de penetração da ponta do System B, melhor a adaptação da obturação ̀̀ paredes do canal.

AL-DEWANI; HAYES; DUMMER ${ }^{2}$ em 2000, estudaram a capacidade de selamento apical e também a qualidade radiográfica de duas técnicas obturadoras: Condensação Lateral e Sistema Ultrafil. Foram utilizados cem dentes unirradiculados. Cinqüenta dentes foram preparados de forma paralela com nenhum ou pouco desgaste na embocadura do canal e cinqüenta de forma cônica com desgaste mais acentuado na embocadura do canal. Ambos os grupos foram divididos em dois subgrupos, de acordo com a técnica de obturação. O cimento obturador empregado foi o Tubliseal. Concluída a etapa de obturação, os dentes foram radiografados e mantidos em umidade por 72 horas. Após este período, foram impermeabilizados e imersos em tinta Nankin durante duas semanas, quando então foram desmineralizados e clareados e a infiltração apical, avaliada num estereomicroscópio. Concluíram que o Sistema Ultrafil apresentou melhor selamento apical porém com pior qualidade radiográfica e maior extrusão de material obturador quando comparado à Técnica da Condensação lateral e que não houve diferença estatisticamente significante na infiltração apical em relação àforma do preparo do canal.

BONETTI FILHO et al. ${ }^{17}$, em 2000, avaliaram o selamento apical de canais radiculares obturados pelas Técnicas da Condensação Lateral e Sistema Microseal. Foram instrumentados trinta incisivos centrais superiores e divididos 
em dois grupos utilizando-se cimento Fill Canal. Concluída a etapa da obturação, os dentes foram impermeabilizados, colocados sob vácuo durante 10 minutos e imersos em azul de metileno a $2 \%$ durante 24 horas. Após esse período os dentes foram seccionados longitudinalmente e a infiltração avaliada com auxílio de um projetor. O sistema Microseal apresentou melhor selamento apical quando comparado com a Técnica da Condensação Lateral ativa.

MAZOTTI $^{68}$, em 2000, estudou a qualidade da obturação de canais radiculares utilizando as técnicas: Condensação Lateral com ultra-som, Thermafil, Microseal e System B. Foi utilizado um modelo de dente seccionado, no qual foram confeccionadas depressões previamente à obturação. Concluiu que o sistema Microseal apresentou melhor homogeneidade da obturação, melhor preenchimento das depressões e menor número de falhas na obturação quando comparado com as demais Técnicas empregadas.

SILVA NETO et al. $^{79}$, em 2001, avaliaram o selamento apical de canais radiculares obturados pelas técnicas System B e Híbrida de Tagger. Foram utilizados trinta e dois caninos humanos extraídos. Foram, instrumentados, irrigados com EDTA, impermeabilizados e divididos em dois grupos. O cimento utilizado foi o Endomethasone. Após as obturações os espécimes foram imersos em corante azul de metileno a $2 \%$ no período de 72 horas e seccionados longitudinalmente. Com o auxílio de um microscópio foi feita a leitura da infiltração do corante. Concluíram que os canais obturados com System B apresentaram melhor selamento apical quando comparados com a Técnica Híbrida de Tagger.

BOWMAN; BAUMGARTNER ${ }^{18}$, em 2002, estudaram a capacidade de preenchimento de sulcos e depressões das obturações executadas com 
System B. Um modelo de dente seccionado foi utilizado, no qual foram confeccionados sulcos e depressões na raiz, a um, três, cinco e sete milímetros aquém do comprimento de trabalho. O terço apical do canal foi obturado com o System B com o condensador inserido em diferentes profundidades: três, quatro e cinco milímetros aquém do comprimento de trabalho. Os outros terços foram obturados pelo sistema Obtura II. A Técnica da Condensação lateral foi utilizada como controle. Terminada a etapa da obturação, as metades do dente foram separadas e a obturação fotografada. Observaram que nas depressões ou nos sulcos confeccionados em todos os níveis na técnica da Condensação Lateral havia apenas, cimento obturador. Os autores concluíram que quando o condensador do System B foi inserido a três milímetros aquém do comprimento de trabalho, promoveu melhor selamento com guta percha nas depressões e sulcos.

BROSCO $^{24}$, em 2002 avaliou in vitro o selamento apical de canais radiculares obturados pelas técnicas:

a) Condensação Lateral realizada com lima tipo Kerr

b) Onda Contínua de Condensação realizada com o System B

c) Sistema Ultrafil

d) Sistema JS Quick-Fill

e) Sistema Microseal associada a um cone principal

Concluiu que as técnicas que apresentaram do melhor para o pior selamento foram: Sistema Microseal, System B, Sistema JS Quick-Fill, Sistema Ultrafil e Condensação Lateral ativa e que nenhuma das técnicas estudadas foi 
capaz de impedir a infiltração apical de corante em todos os dentes.

GENÇOGLU et al. ${ }^{42}$, em 2002, compararam o selamento apical propiciado pelas técnicas: Thermafil, Quick-Fill, System B e condensação Lateral. Quarenta dentes anteriores superiores com canais retos foram selecionados, dez para cada Técnica obturadora. A Técnica Instrumental foi a Escalonada regressiva sendo a lima memória a de número 60 . A solução irrigadora utilizada foi o Hipoclorito de Sódio a 5,25\% e o cimento obturador Kerr Pulp Canal Sealer. Concluíram que as Técnicas Thermafil e Quick Fill foram significantemente melhores que System B e Condensação Lateral.

\subsection{SELAMENTO APICAL EM FUNÇÃO DOS CIMENTOS OBTURADORES}

A preocupação em selar hermeticamente o sistema de canais radiculares com o intuito de se evitar a infiltração apical remota de longa data.

GROSSMAN $^{44}$, em 1939, analisou o selamento hermético proporcionado por materiais seladores provisórios, frente a infiltração de solução corante, saliva com corante e bactérias. Foram avaliados a guta-percha, silicona temporária, cimento de oxifosfato de zinco e Pró tem, sendo que esses materiais foram colocados sozinhos ou associados. O corante utilizado foi o azul de metileno e os materiais foram inseridos em tubos, ao invés de dentes. Constatouse que os materiais estudados não são impermeáveis ao corante e àpenetração bacteriana; em contato com a saliva ocorreu menos infiltração e que os cimentos contendo óxido de zinco e eugenol foram mais efetivos que os cimentos com oxifosfato. 
HOLLAND et $\mathrm{al}^{49}$, em 1974 avaliaram, in vitro, por meio da penetração de solução de lodo 131, a capacidade seladora dos cimentos: de óxido de zinco e eugenol, Rickert, Alpha canal, Piocidina e pasta de Wach. Utilizaram 210 dentes unirradiculados sendo que 10 serviram como controle. Após o preparo biomecânico os dentes foram divididos em função dos materiais a serem utilizados, de suas consistências (fluido ou consistente), e das técnicas de obturação: cone único e pela condensação lateral. Empregaram quarenta dentes para cada cimento sendo dez para cada subgrupo. Após a obturação, os dentes foram imersos na Solução de lodo131 a $37^{\circ} \mathrm{C}$ por 24 horas. Decorrido esse período os dentes foram lavados, incluidos em resina e seccionados longitudinalmente. Os espécimes foram então radiografados e as imagens projetadas com aumento de 35 vezes e então, mediu-se a infiltração com um paquímetro. Os resultados mostraram que houve maior infiltração com significância estatística entre a forma física do cimento (fluido ou consistente) e a técnica de obturação. As menores infiltrações ocorreram com a pasta de Wach fluída pela técnica de Condensação Lateral, no cimento de Rickert consistente em ambas as técnicas e na consistência fluida pela condensação lateral e no Alpha Canal fluido e condensação lateral.

PITT FORD ${ }^{75}$, em 1979, comparou o selamento apical proporcionado por dois cimentos ionoméricos experimentais com os cimentos AH26, Spad e o Methode Z. Foram utilizados dentes humanos unirradiculados, cujos canais foram preparados, e após impermeabilização externa da raiz, obturados com cone de guta-percha ou de prata e os cimentos citados. Após as obturações, os dentes foram imersos em solução aquosa de eosina para marcar a 
infiltração. Transcorrida 48 horas, os dentes foram lavados, seccionados longitudinalmente, fotografados e com o auxilio de uma régua mediram a infiltração do corante. O cimento AH26 apresentou melhor selamento. Os cimentos ionoméricos experimentais Aspa IV SnO e Aspa IV selaram melhor nos grupos obturados pela técnica do cone único. Os cimentos Spad e Methode Z apresentaram os piores resultados.

ALEXANDER; GORDON ${ }^{3}$, em 1985, compararam o selamento apical de dois cimentos obturadores com hidróxido de cálcio, sendo eles o Sealapex e o CRCS com aquele selamento proporcionado pelo cimento de Grossman. Utilizaram trinta dentes unirradiculados cujos canais foram instrumentados e obturados pela técnica da condensação lateral, variando-se o cimento, seguindo a seguinte ordem: Grupo I: Cimento de Grossman; Grupo II: Cimento Sealapex; Grupo III: Cimento CRCS. Os espécimes foram mantidos em um encubador a $37^{\circ} \mathrm{C}$ num recipiente com algodão úmido durante seis dias para a presa dos materiais. Após esse período, os dentes foram imersos em solução aquosa de azul de metileno a $2 \%$ a $37^{\circ} \mathrm{C}$ por seis dias. Concluído o período, os dentes foram lavados, seccionados e, então avaliou-se a magnitude de infiltração num aumento de 12,5X. O cimento Sealapex apresentou melhor selamento, seguido do cimento de Grossman. O cimento CRCS apresentou os piores valores.

LEAL et al. ${ }^{62}$, em 1987, avaliaram in vitro o selamento apical proporcionado pelos cimentos Sealapex, $\mathrm{AH} 26$ silver free e Fill canal e também a influência do tempo de armazenagem na infiltração. Noventa incisivos superiores tiveram os canais instrumentados, e após a impermeabilização das superfícies externas foram divididos em 3 grupos de 30 dentes, em função do cimento 
obturador. Imediatamente após a obturação, quinze dentes de cada grupo foram imersos em solução corante de Rhodamine B a $2 \%$ por 7 dias e os outros quinze foram imersos em soro fisiológico por 30 dias e posteriormente, colocados no mesmo corante por mais 7 dias. Após esse período, os dentes foram seccionados longitudinalmente para avaliação da magnitude da infiltração. Os cimentos AH 26 silver free e o Sealapex apresentaram os menores índices de infiltração enquanto que o Fill canal, os maiores. O tempo de armazenagem teve influência significativa sobre a infiltração.

KUGA; MORAES; BERBERT ${ }^{58}$ em 1988, estudaram a influência do acréscimo de iodofórmio, nas proporções de 2:1 e 4:1 em volume, no selamento apical proporcionado pelo cimento Sealapex. Foram utilizados 24 caninos humanos cujos forames foram padronizados até a lima do tipo Kerr de número 35, e os canais instrumentados pela técnica escalonada regressiva. Os espécimes foram impermeabilizados e os canais obturados pela técnica da Condensação Lateral passiva, utilizando-se o cimento Sealapex puro ou acrescido de lodofórmio nas proporções citadas. Após a obturação, selaram a coroa dos dentes e imergiram os mesmos em solução aquosa de azul de metileno a $2 \%$ por 7 dias. Após esse período, os dentes foram seccionados e analisados quanto ànfiltração linear. Os autores concluíram que o acréscimo de iodofórmio melhorou o selamento do cimento e que, inclusive, na proporção de 2:1 houve diferença significante em relação ao puro.

NEGM $^{72}$, em 1989, estudou o efeito da contaminação por sangue humano e umidade na habilidade de selamento de seis cimentos obturadores, normalmente utilizados, que foram: o Tubliseal, Diaket, $\mathrm{AH} 26$, Nogenol, Roth e o 
Endomethasone. Os canais foram obturados pela técnica da condensação lateral com os cimentos e cones de guta-percha.. Após a obturação os dentes foram imediatamente imersos em sangue, solução salina ou mantidos secos por 2 horas. Após esse período, todos os espécies foram imersos em solução aquosa de azul de metileno a $2 \%$, por 1 hora. A comparação do selamento foi feita pela observação da penetração do corante ao redor do material obturador. Sob todas as condições, o Tubliseal exibiu a menor quantidade de infiltração, seguido pelo AH 26. Na profundidade de penetração de corante entre o Diaket e o Tubliseal, não houve diferença significante seja em condições secas ou úmidas. Embora o AH 26, Nogenol, Roth e Endomethasone tenham demonstrado habilidades comparáveis de selamento sob condições secas, a habilidade de selamento do AH 26 e do Diaket foram superiores æquelas do Nogenol, Roth e Endomethaso ne em contaminação pela umidade. Uma queda significante no selamento, proporcionado pelo AH 26, Diaket, Roth e Endomethasone foi observada quando estes materiais foram imersos em sangue. Por outro lado, esta condição não causou mudanças significantes na habilidade de selamento do Nogenol.

HOLLAND et al ${ }^{50}$, em 1991, estudaram a infiltração marginal após a obturação dos canais de dentes humanos extraídos, com diferentes cimentos obturadores: óxido de zinco e eugenol, Fill canal, Rickert, AH 26, Sealapex, CRCS, New $B_{2}$ e um cimento experimental. Com a intenção de avaliar melhor quantitativamente a infiltração marginal ocorrida, os espécimes foram mergulhados em solução de azul de metileno em ambiente com vácuo,por 10 minutos. Após esse período, os dentes foram seccionados longitudinalmente e dimensionada a infiltração, com o auxílio de uma ocular micrometrada, 
submetendo-se os dados àanálise estatística. Observaram que os cimentos a base de hidróxido de cálcio e resina epóxica, apresentaram menor grau de infiltração que aquelas àbase de óxido de zinco e eugenol.

LIMKANGWALMONGKOL et al. ${ }^{66}$, também em 1991, estudaram o selamento apical proporcionado pelos cimentos Apexit, Sealapex, AH 26 e Tubliseal em obturações endodônticas realizadas pela técnica da Condensação Lateral. Foram utilizados 125 dentes, cujos canais foram instrumentados pela técnica escalonada regressiva e, então, divididos em 5 grupos, em função dos quatro materiais estudados e um grupo que foi obturado sem cimento. Concluídas as obturações os dentes foram mantidos a $37^{\circ} \mathrm{C}$ por 48 horas para presa dos materiais. Após esse período, impermeabilizaram os dentes e imergiram-nos em solução aquosa de azul de metileno a $2 \%$ e colocaram em centrífuga por 3 minutos. Os espécimes foram seccionados transversalmente e observaram o nível de infiltração do corante. Os resultados mostraram que o AH 26 infiltrou 0,82mm; Apexit 1,67mm; Sealapex 2,28mm; Tubli - Seal 1,95mm e o grupo sem cimento $8,37 \mathrm{~mm}$. Concluíram que o cimento deve ser empregado com guta percha na condensação lateral e que o $A H 26$ apresentou um selamento significantemente melhor do que os outros materiais.

SAHLI et al. $^{76}$, em 1992, estudaram o selamento apical proporcionado por vários cimentos obturadores, utilizando um novo método baseado no uso de um radioisótopo e uma técnica de detecção externa. Utilizaram 150 dentes unirradiculados que tiveram os canais instrumentados e, posteriormente, divididos em 6 grupos experimentais e dois grupos controles, em função dos cimentos a serem utilizados, sendo dois à base de óxido de zinco e 
eugenol, dois de resina e dois de hidróxido de cálcio. Para o controle positivo só se empregou guta-percha, e o controle negativo teve o forame selado com verniz. A técnica utilizada na obturação foi a condensação lateral e, uma vez obturados, os canais e após a presa dos cimentos, imergiram os ápices dos espécimes em uma solução contendo o radioisótopo metaestável TC. Verificaram que nenhuma infiltração ocorreu no controle negativo. Houve diferença estatística entre os grupos experimentais e o controle positivo. O melhor selamento ocorreu com 0 Sealapex que se diferenciou dos demais. $\mathrm{O}$ AH 26 , Tubli-seal e Diaket não se diferenciaram entre si, porém, foram estatisticamente superiores ao CRCS e Endomethasone que demonstraram os piores resultados.

SMITH; STEIMAN ${ }^{81}$, em 1994, estudaram in vitro, a microinfiltração apical de quatro cimentos obturadores de canais radiculares, utilizando o método de infiltração de corante e clarificação da estrutura dentária para avaliar a penetração do corante. Os cimentos Ketac-Endo, Tubliseal (fórmula velha) Tubliseal (fórmula nova) e o cimento Roth 801 foram comparados com um grupo controle onde não se utilizou cimento. A Técnica obturadora foi condensação lateral. Dentes unirradiculados tiveram os canais instrumentados, obturados de acordo com o grupo e foram estocados por 4 dias. Após esse período, os dentes foram impermeabilizados e imersos em corante Tinta da Índia, durante 8 dias. Posteriormente, os dentes foram desmineralizados, clareados e, então, se determinou a penetração linear do corante. Os autores observaram que todos os grupos com cimento selaram significantemente mais que o grupo sem cimento. Não houve diferença significante entre as fórmulas do Tubliseal. Já e o cimento Ketac- Endo apresentou os piores resultados. 
BONETTI FILHO et al. ${ }^{15}$, em 1995 estudaram o selamento apical proporcionado pelos cimentos Sealer 26 e Ketac - Endo, comparando-os ao cimento Fill canal. Foram utilizados 39 incisivos superiores, instrumentaram-se os canais de forma a transpassar o forame em $1 \mathrm{~mm}$ até a lima do tipo Kerr de $\mathrm{n} . \stackrel{0}{50}$. Cones de $n .-50$ foram testados e transpassados além do ápice, cortando-se o excesso com lâmina de bisturi. A técnica de obturação foi da Condensação lateral, variando-se os cimentos. Os espécimes foram impermeabilizados e imersos em solução de azul de metileno a $2 \%$ a uma temperatura de $37^{\circ} \mathrm{C}$ por 24 horas. Em seguida, os dentes foram lavados, raspados e seccionados para mensuração da infiltração, que foi realizada com o aparelho "Profile projector" com aumento de 20X. Observaram que o Sealer 26 apresentou melhor selamento, seguido do Fillcanal. O cimento Ketac-Endo apresentou os piores resultados.

BRAMANTE; DUARTE; BRAMANTE ${ }^{20}$, em 1996, verificaram o selamento apical proporcionado pelos cimentos com hidróxido de cálcio: Apexit, Prócanal e Set sealer, comparando ao do cimento de óxido de zinco e eugenol. Quarenta dentes unirradiculados tiveram seus forames apicais padronizados até a lima do tipo Kerr n.. 30, transpassados $1 \mathrm{~mm}$ além do comprimento real do dente. Instrumentaram os canais pela técnica escalonada regressiva, sendo a lima do tipo Kerr de número 50 o instrumento memória, e então, impermeabilizaram as superfícies externas e obturaram pela técnica do cone único, variando os cimentos estudados. Após a obturação, selaram as coroas e imergiram os espécimes em solução de azul de metileno a $2 \%$ em uma temperatura de $37^{\circ} \mathrm{C}$, por 7 dias. Os dentes foram, então, lavados e seccionados para análise da 
infiltração. Os autores observaram que o Apexit apresentou os melhores resultados, seguido do Pró-canal. O cimento Set sealer apresentou os piores resultados.

HOLLAND et al. ${ }^{51}$, também em 1996, estudaram o selamento apical proporcionado por quatro cimentos àbase de hidróxido de cálcio: Sealapex, CRCS, Sealer 26 e Apexit, comparando os resultados àvueles oferecidos pelo óxido de zinco e eugenol (grupo controle). Foram empregados 50 dentes unirradiculados que após o preparo biomecânico dos canais foram obturados pela Técnica da Condensação lateral. Após a obturação os dentes foram armazenados em água durante 24 horas e, posteriormente, sofreram ação de um sistema a vácuo por 10 minutos para então serem imersos em azul de metileno a 2\% por 12 horas. Os dentes foram seccionados e a infiltração analisada com auxílio de estereomicroscópio munido de ocular micrometrada. Os resultados mostraram que os cimentos com hidróxido de cálcio selaram mais que o de óxido de zinco e eugenol. Entre os cimentos com hidróxido de Cálcio, o CRCS apresentou, estatisticamente, piores resultados que os demais.

TANOMARU FILHO et al. ${ }^{84}$, em 1996, estudaram a capacidade seladora apical de 2 cimentos obturadores com hidróxido de cálcio sendo eles o Sealapex e o Sealer 26 comparando-os com o cimento de óxido de zinco e eugenol. Foram empregados trinta dentes unirradiculados que tiveram seus forames padronizados até a lima do tipo Kerr de n.ํㅜ 30, ultrapassando $1 \mathrm{~mm}$ além do comprimento real do dente. Os canais foram instrumentados pela Técnica Escalonada regressiva tendo como instrumento memória, a lima do tipo Kerr de ก. ${ }^{\circ}$ 50. Os espécimes foram impermeabilizados e os canais obturados pela técnica 
do cone único, variando-se os cimentos. As coroas foram, então, seladas e os dentes imersos em solução de azul de metileno a $2 \%$ a $37^{\circ} \mathrm{C}$, por 7 dias. Após esse período, os dentes foram lavados e seccionados no sentido vestíbulo lingual. Os resultados mostraram que o Sealer 26 apresentou melhor selamento, diferenciando-se estatisticamente dos demais.

ALMEIDA $^{5}$, em 1997, em sua tese de doutorado, estudou a capacidade de selamento apical dos cimentos AH Plus, Ketac-Endo e o Fill canal. Noventa e nove incisivos centrais superiores humanos extraídos foram divididos em três grupos de trinta e três dentes cada, que foram instrumentados com limas Nitiflex até o número 55 , ultrapassando-se $2 \mathrm{~mm}$ do forame apical. Os canais foram obturados com guta percha e os cimentos em estudo pela técnica da Condensação Lateral. Após as obturações os dentes foram impermeabilizados com esmalte de unha exceto no $\mathrm{mm}$ apical. Os espécimes foram imersos no corante azul de metileno a $2 \%$ por 24 horas. Após esse período os dentes foram lavados por mais 24 horas e seccionados longitudinalmente. Determinou a penetração do corante com auxílio de um perfilômetro e os dados submetidos a análise estatística. Concluiu que o cimento AH Plus apresentou os menores índice de infiltração, diferenciando-se estatisticamente do Fill canal e Ketac-Endo.

ZMENER et al. ${ }^{95}$, em 1997, estudaram a capacidade seladora de um novo cimento endodôntico a base de resina epóxica, o AH Plus, utilizando o AH26 como controle e parâmetro de comparação. Foram empregados 72 dentes unirradiculados, cujos canais foram instrumentados pela Técnica Escalonada Regressiva. A técnica de obturação foi a Condensação Lateral. Os espécimes foram estocados por 48 horas a $37^{\circ} \mathrm{C}$ em $100 \%$ de umidade para permitir a presa 
dos cimentos. Após esse período, os dentes foram imersos em solução corante azul de metileno a 5\% por 2, 4 e 10 dias. No final de cada período removeram os dentes do corante, lavaram e seccionaram longitudinalmente e determinaram a infiltração num estereomicroscópio. Os autores concluíram que o AH26 selou estatisticamente melhor que o AH Plus nos três períodos analisados.

DUARTE $^{33}$, em 1999, em sua tese de doutorado, avaliou a capacidade seladora do cimento AH Plus acrescido de 5 e 10\%, em peso, de hidróxido de cálcio. Foram utilizados 80 dentes caninos e a padronização do forame foi realizada dilatando o canal até a lima do tipo Kerr de n.ํ 30 pela técnica escalonada regressiva estabelecendo o degrau apical de instrumentação $1 \mathrm{~mm}$ aquém da extensão total e tendo como instrumento memória a lima do tipo Kerr de n.ํ 45. Após a instrumentação, os dentes foram impermeabilizados e divididos em 4 grupos de vinte dentes, de acordo com o cimento obturador empregado: grupo I: cimento AH Plus; grupo II: cimento AH Plus com 5\% de hidróxido de cálcio (Merck); grupo III: cimento AH Plus com 10\% de hidróxido de cálcio (Merck) e grupo IV: controle: óxido de zinco e eugenol. A técnica de obturação foi a do cone único. Após a obturação, as aberturas coronárias foram seladas com cimpat e as coroas impermeabilizadas com cera fundida. Os dentes foram imersos em solução aquosa de azul de metileno a $2 \%$ a $37^{\circ} \mathrm{C}$ durante 7 dias. Após esse período os espécimes foram lavados, livrados da impermeabilização e clivados no sentido vestíbulo-lingual após confecção de sulcos nas faces vestibular e lingual, obtendo-se duas hemissecções sendo que a mais espessa foi conservada para leitura da infiltração. O autor concluiu que o acréscimo do hidróxido de cálcio no cimento AH Plus nas proporções de $5 \%$ e $10 \%$ em peso, favoreceu uma melhora 
significante da capacidade seladora do material sendo que a $5 \%$ ocorreu infiltração ligeiramente menor que a 10\%.

ALMEIDA et al. ${ }^{6}$, em 2000, estudaram a capacidade de selamento apical dos cimentos Fillcanal, Ketac-Endo e AH Plus em dentes obturados pela técnica da condensação lateral da guta-percha. Como agente identificador da infiltração foi utilizado o corante azul de metileno a $2 \%$ no qual os dentes ficaram imersos por 24 horas. Os espécimes foram seccionados no sentido do longo eixo da raiz e os níveis de infiltração aferidos. Os autores observaram a superioridade do cimento AH Plus sobre os demais cimentos testados.

BRANDÃO; MORAES; BRAMANTE ${ }^{23}$, em 2001, compararam a capacidade seladora apical de dois cimentos endodônticos ionoméricos: Ketac Endo e Vidrion com o Sealer 26. O corante utilizado foi o azul de metileno a 1\% e a técnica obturadora do cone único em canais unirradiculados humanos. Concluíram não haver diferenças estatisticamente significante na infiltração apical entre os cimentos ionoméricos e que houve essa diferença entre os mesmos e o cimento Sealer 26, que apresentou menores médias de infiltração.

BASSILI $^{10}$, em 2002, avaliou in vitro, a influência do tratamento das paredes de canais radiculares, previamente àobturação, com a aplicação do laser de Nd: YAG ou solução de EDTA trissódico, na capacidade seladora de obturações realizadas com dois tipos de cimento: AH Plus e Endofill, e a possível interação entre os tratamentos e os cimentos utilizados. Concluiu que o cimento AH Plus apresentou melhor capacidade de selamento apical quando comparado com o cimento Endofill, independente do tratamento realizado 
previamente àobturação. 


\section{PROPOSIÇÃO}

O objetivo deste trabalho foi avaliar o selamento apical de obturações de canais radiculares que sofreram desvio apical de instrumentação (ZIP), realizadas com diferentes técnicas obturadoras e dois tipos de cimento. 


\section{MATERIAL E MÉTODOS}

Foram utilizadas 80 raízes mésio - vestibulares de dentes molares superiores humanos, extraídos e mantidos em solução de formalina a 10\% até o momento de uso e pertencentes ao arquivo de dentes da disciplina de Endodontia da FOB - USP. Essas raízes, com canais únicos e curvos, foram inicialmente separadas do restante do dente, utilizando-se de disco de carborundum em baixa rotação. O preparo de todos os canais foi realizado de maneira idêntica, utilizandose da técnica escalona regressiva, tendo como instrumento memória a lima do tipo

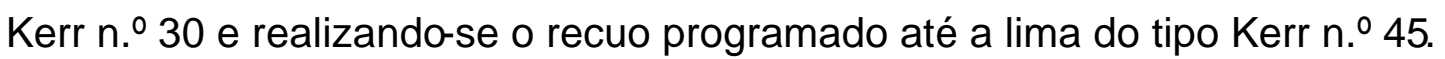

\subsection{Seqüência do preparo biomecânico dos Canais Radiculares}

Inicialmente uma lima do tipo Kerr de $n^{\circ}$ 8, munida de limitador de penetração, foi introduzida ao longo do canal radicular, previamente preenchido com hipoclorito de sódio a $1 \%$, até que a extremidade de sua guia de penetração fosse visualizada ao nível do forame apical. O limitador de penetração foi, então, apoiado no ponto de referência mais saliente, a lima retirada do canal e a distância entre o limitador de penetração e sua extremidade foi medida e anotada. Esta medida caracterizou o comprimento total da raiz CRT e, conseqüentemente, do canal radicular.

Na seqüência, foram introduzidas as limas do tipo Kerr nº 10 e 15 na

\footnotetext{
* Myako do Brasil ind e com. Ltda. São Paulo
} 
mesma extensão estabelecida. Diminuindo-se $1 \mathrm{~mm}$ daquela extensão, a lima do tipo Kerr no 15 foi posicionada para, então, proceder-se a uma tomada radiográfica do conjunto raiz / lima. Após a tomada radiográfica, mantendo-se esta nova extensão, prosseguiu-se com o preparo do canal radicular até atingir a lima do tipo Kerr no 30, objetivando-se a obtenção do degrau apical. Prosseguindo, dentro da técnica escalonada regressiva fez-se o recuo programado até a lima do tipo Kerr nำ 45, mantendo-se a de nำ 30 como instrumento de memória.

Vale ressaltar que, contrariando as indicações, os instrumentos não foram pré-curvados com o intuito de provocar deliberadamente desvios de instrumentação apical, (Zip). Após o término da instrumentação a lima memória (n- 30) foi posicionada no canal radicular apoiada no degrau apical e uma segunda tomada radiográfica foi executada.

Para as tomadas radiográficas no início (lima no 15) e no final (lima $\left.n^{\circ} 30\right)$ da instrumentação certos cuidados foram tomados objetivando-se manter sempre a mesma posição da raiz em relação ao filme e ao cilindro localizador de raios $\mathrm{X}$, bem como a distância foco / filme. Para tal, foram confeccionadas bases de acrílico individuais, que possibilitaram posicionar as raízes sempre na mesma posição para a tomada radiográfica, bem como a mesma direção dos raios $\mathrm{X}$. (Figuras 1 a 3) 

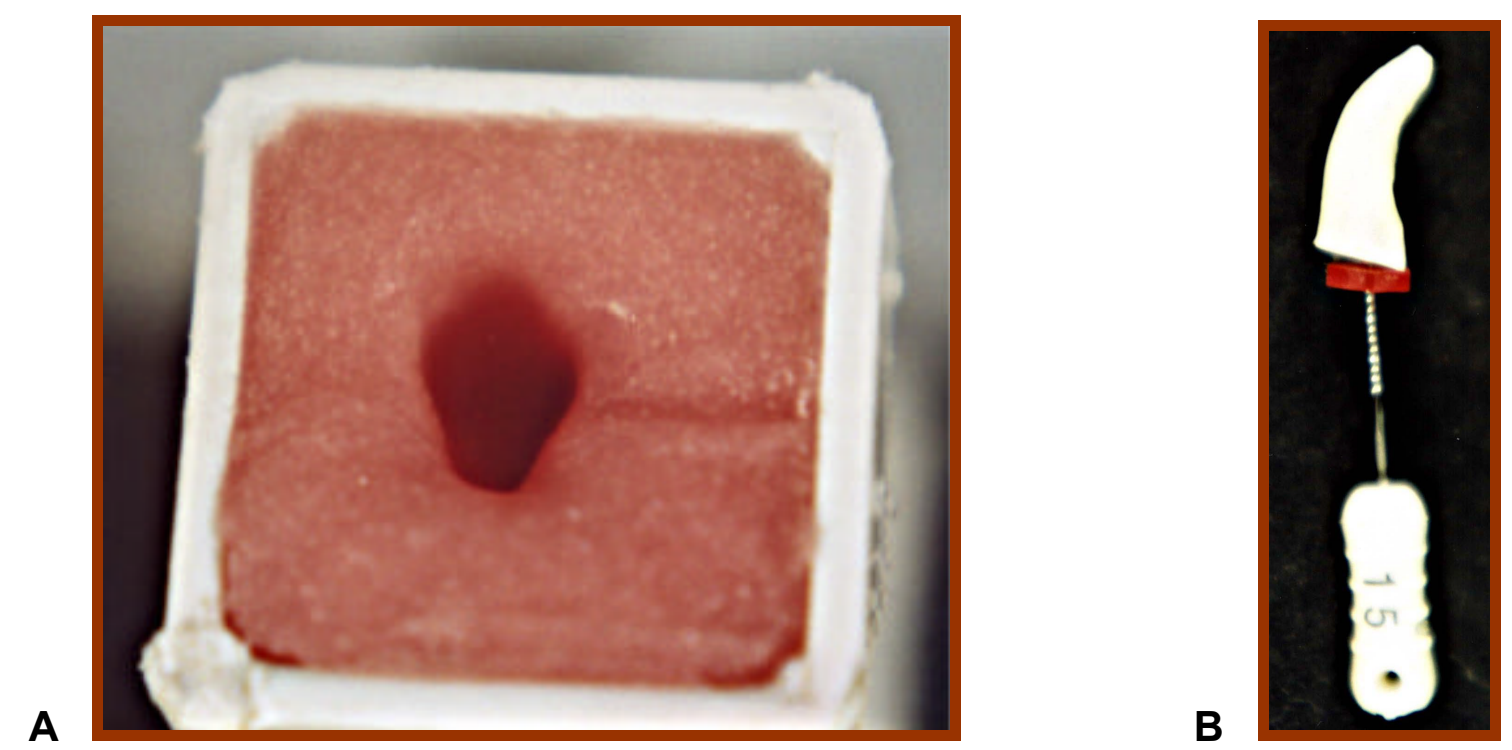

Figura 1 - A) Base de resina acrílica para posicionamento das raízes sempre na mesma posição nas tomadas radiográficas. B) Raiz mésio-vestibular com a lima do tipo Kerr $n .^{\circ} 15$ ajustada no canal, para auxiliar a confecção do leito necessário à sua reposição

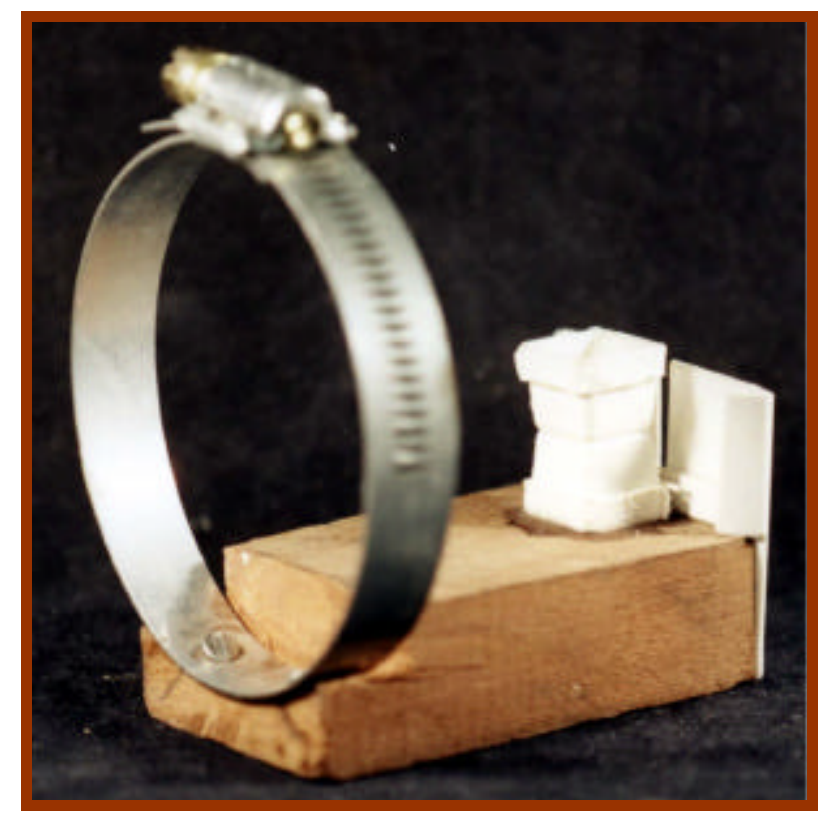

Figura 2 - Dispositivo utilizado nas tomadas radiográficas para verificação da formação do "ZIP" 


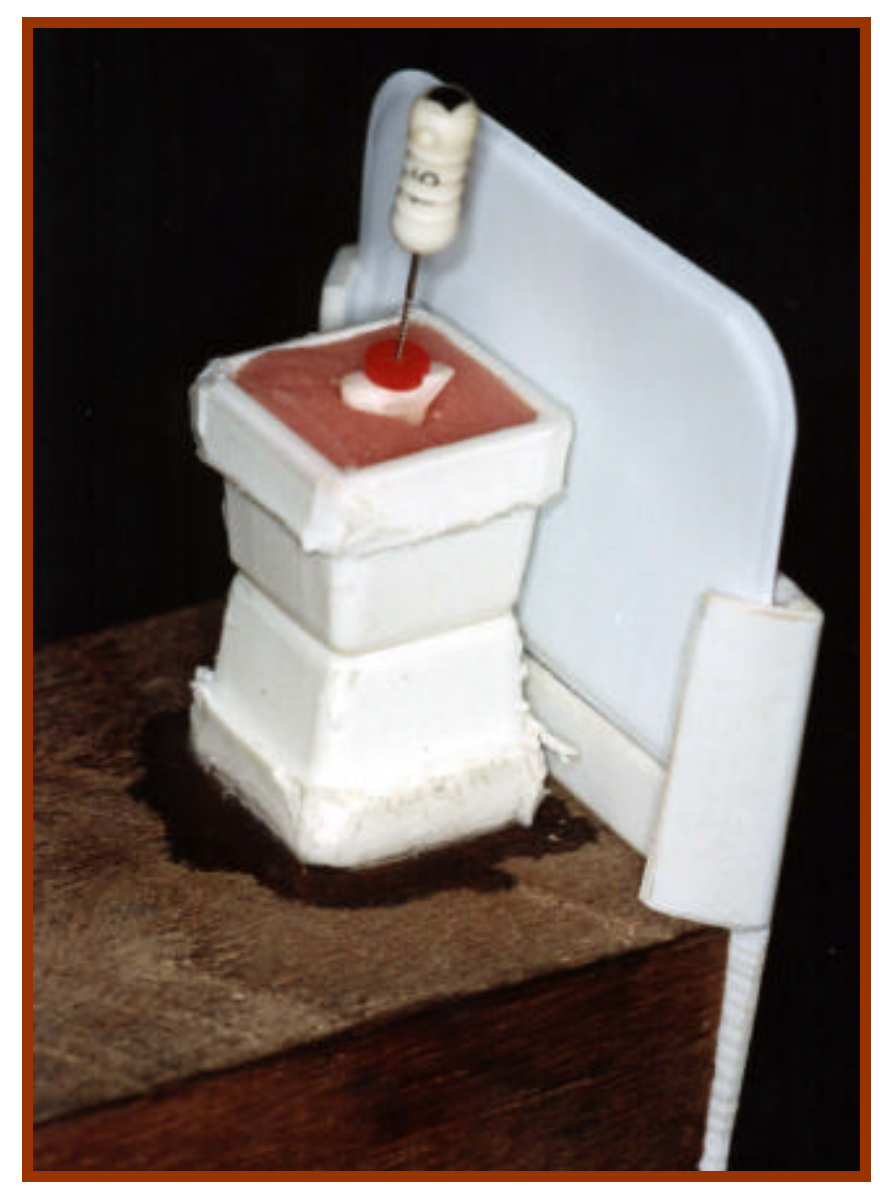

Figura 3 - Raiz posicionada na base de acrílico com uma lima Kerr n. ${ }^{\circ} 15$ no momento da odontometria

As raízes foram posicionadas de maneira que a incidência dos raios X ocorresse sempre frontal àface vestibular. A distância foco / filme foi de $20 \mathrm{~cm}$. Os filmes utilizados foram do tipo Ekta Speed (Kodak). O aparelho de raios $X$ foi da marca Dabi (60 KVp) e os filmes processados nas soluções Kodak utilizandose a técnica temperatura / tempo.

As radiografias, assim obtidas, foram montadas em molduras, para diapositivos e as imagens radiográficas projetadas, utilizando-se de um projetor de diapositivos da marca Kodak, com um aumento de vinte vezes, 
sobre um papel branco onde se copiou, com um lápis, a imagem do contorno radicular e da lima no 15 , num primeiro momento. Na seqüência, sobre essa cópia foi projetada a imagem da segunda radiografia (lima $n^{\circ}$ 30). Em cor diferente foi demarcada a imagem da lima no 30 . A diferença de posicionamento das extremidades das limas no 15 e 30 caracterizou o desvio apical de instrumentação (Figura 4 e 5).

A

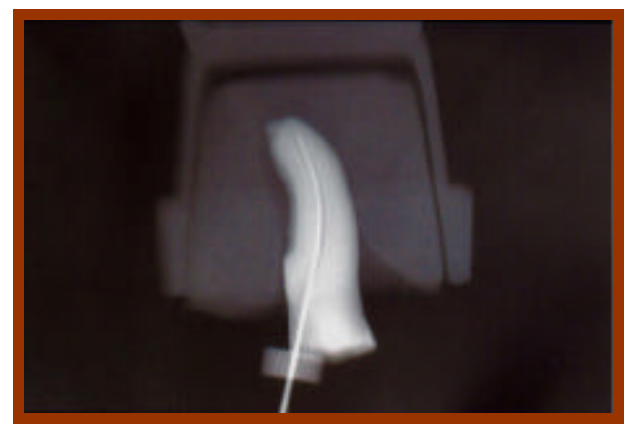

B

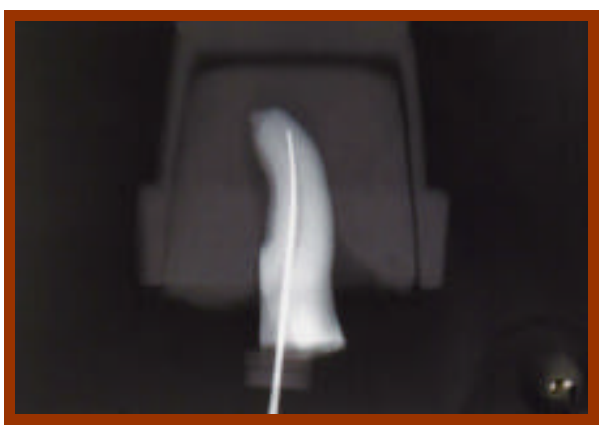

Figura 4 - Imagens radiográficas demonstrando a formação do "ZIP" de instrumentação. A - antes (lima n. $\left.{ }^{\circ} 15\right)$. B - após (lima n. ${ }^{\circ} 30$ ) 

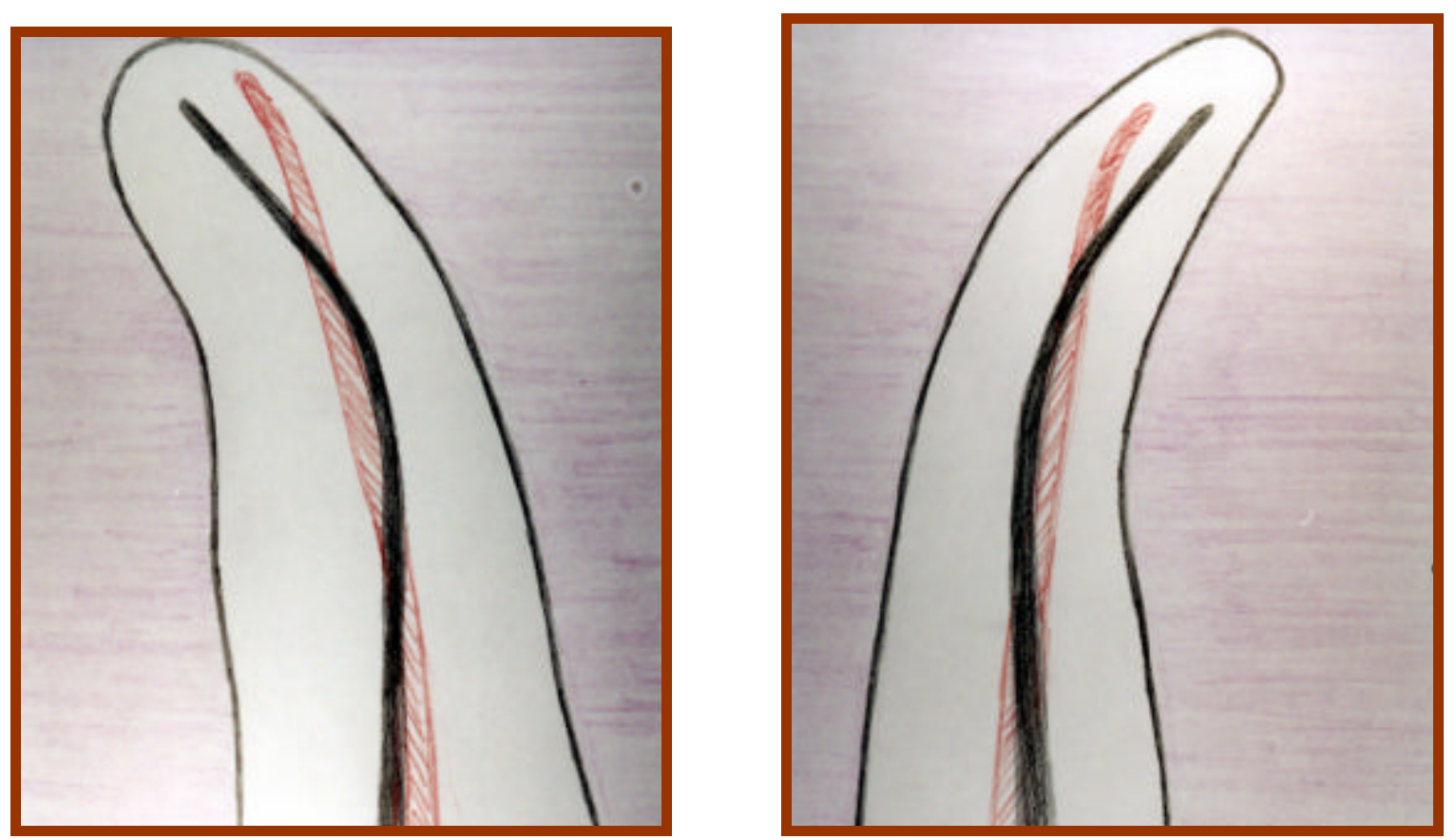

Figura 5 - Desenhos do contorno das raízes com lima do tipo Kerr n. ${ }^{0} 15$ (preto) e n. ${ }^{\circ} 30$ (vermelho), posicionadas no canal radicular. A diferença de posicionamento das extremidades das limas caracterizou o desvio apical de instrumentação

Durante o preparo biomecânico dos canais radiculares foi realizada irrigação simples com hipoclorito de sódio a 1\% utilizando-se seringa Luer Look, de bico metálico, munida de cânula 25/3. A cada troca de instrumento, irrigou-se com $1 \mathrm{ml}$ da solução e ao final da instrumentação com 3ml de soro fisiológico.

A seguir cada canal foi seco por aspiração e, então, preenchido com EDTA de Ostby (Odacham) por 3 minutos. Após esse período o EDTA foi neutralizado irrigando-se o canal com 3ml de soro fisiológico. 


\subsection{Impermeabilização das superfícies externas das raízes}

As superfícies externas das raízes foram impermeabilizadas por meio da aplicação de duas camadas de Araldite* de presa lenta e uma camada de esmalte para unhas ${ }^{\star *}$. Tal impermeabilização foi realizada de maneira a deixar exposto cerca de $0,5 \mathrm{~mm}$ ao redor do forame apical bem como nas proximidades da embocadura do canal radicular.

\subsection{Divisão dos elementos radiculares em função dos cimentos e das técnicas de obturação preconizados.}

As raízes foram divididas em 02 grupos de 40 elementos de acordo com os cimentos utilizados na obturação. Cada grupo foi dividido em 4 subgrupos, em função das técnicas obturadoras preconizadas, nessa seqüência:

G1 - Cimento de óxido de zinco e eugenol* (Figura 6)

G1-1- Técnica da condensação lateral.

G1-2- Técnica da condensação lateral com moldagem térmica direta do cone principal.

G1-3- Técnica do Thermafil.

G1-4- Técnica do System B.

\footnotetext{
* Adesivo epóxi - Ciba especialidades químicas Ltda - Taboão da Serra - S.P.

** Colorama Ceil - Com. Exp. Ind. Ltda - São Paulo - S.P.
} 


\section{G2 - Cimento AH plus ${ }^{* *}$ com $5 \%$ de hidróxido de Cálcio (Figura 7)}

G2-1- Técnica da condensação lateral.

G2-2- Técnica da condensação lateral com moldagem térmica direta do cone principal.

G2-3- Técnica do Thermafil.

G2-4- Técnica do System B.

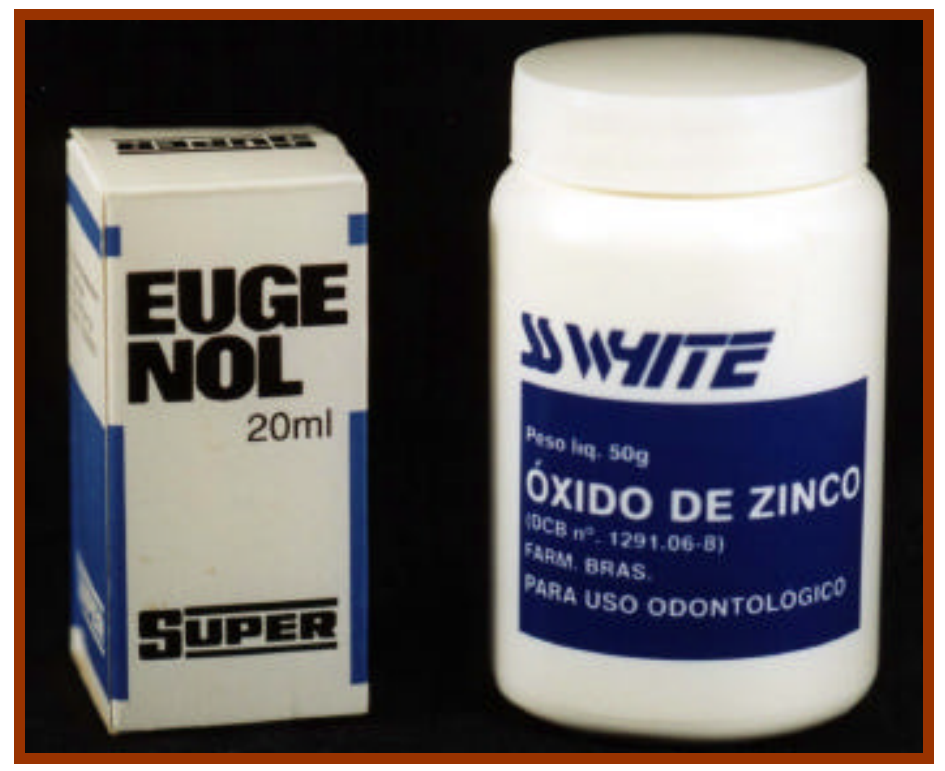

Figura 6 - cimento de óxido de zinco e Eugenol 


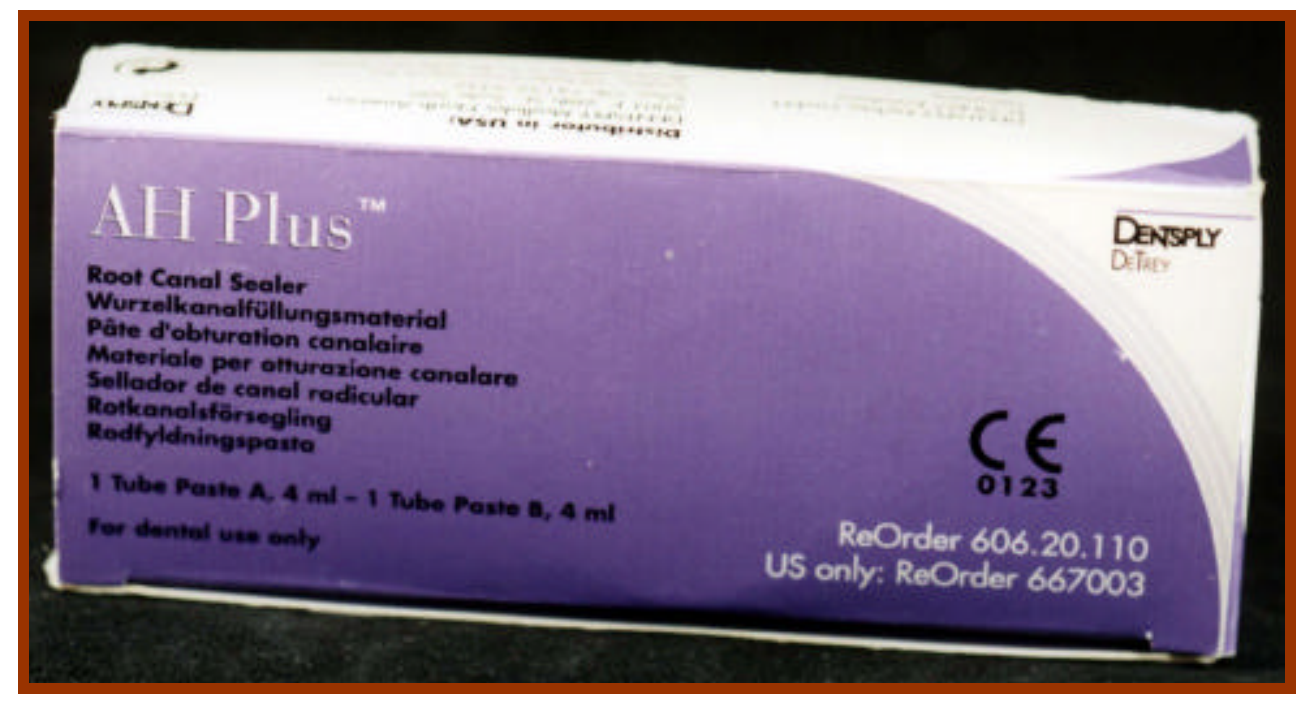

Figura 7 - cimento AH Plus

\subsection{Procedimentos de Obturação}

Para o grupo 1 o cimento utilizado foi o cimento de Óxido de Zinco e Eugenol na proporção de 1,8 gramas de pó para $1 \mathrm{ml}$ de eugenol. No grupo 2 o cimento foi o AHPLUS com 5\% de hidróxido de cálcio, pesado e espatulado, seguindo orientações de DUARTE $^{33}$. Os cones principais de guta - percha de calibre n.30 foram da Dentsply para os subgrupos G1-1, G1-2, G2-1 e G2-2; e os mesmos foram adaptados ao nível do degrau apical. Nos subgrupos G1-3 e G2-3 foram utilizados os obturadores Thermafil* de número 30 com carregador de plástico.

\footnotetext{
* Maillefer - Thermafil - Suíça
} 
Para a obturação dos canais das raízes dos subgrupos G1-4 e G2-4 foram utilizados os cones Autofit ${ }^{\star}$; do próprio fabricante do aparelho utilizado para a realização da obturação. Antes das obturações do experimento serem realizadas, foi feito um treinamento prévio do operador, para que houvesse uma menor interferência do fator domínio de Técnica nos resultados finais.

As raízes foram fixadas em uma Morsa* ${ }^{\star *}$ tomando-se o cuidado de colocar uma atadura de gaze entre os mordentes e a raiz para não danificar a impermeabilização.

\subsection{Obturação dos canais das raízes dos grupos G1-1 e G2-1.}

Após o correto proporcionamento dos cimentos e a devida espatulação procedeu-se ao assentamento do cone principal de guta-percha. Este foi assentado por meio da técnica clássica. Assim, com auxílio de uma lima do tipo Kerr no 30 de $21 \mathrm{~mm}$, uma pequena quantidade de cimento foi levada ao interior do canal radicular, procurando-se tocar todas as paredes do mesmo. Feito isso o cone foi acentado naturalmente. Na seqüência foi realizada a condensação lateral, utilizando-se como espaçador a própria lima do tipo Kerr $\mathrm{n} \cong 30$ de $21 \mathrm{~mm}$ e cones secundários $X F^{* * *}$. Em seguida, o excesso de guta percha foi removido com um instrumental aquecido e condensado verticalmente com um condensador dígitopalmar número 2.

\footnotetext{
* Analytic Tecnology - Fenton, Missouri

** Somar, n.ำ1. Ind. Brasileira

*** Dentsply
} 


\subsection{Obturação dos canais das raízes dos grupos G2-1 e G2-2}

Foram praticamente os mesmos procedimentos realizados para os grupos anteriores, diferenciando-se apenas no tratamento do cone principal; imediatamente antes do acentamento do cone, a extremidade de uma espátula tipo Holemback foi aquecida na chama de uma lamparina a álcool e nela foi tocada rapidamente a extremidade apical do cone de guta percha. O cone, com sua ponta ligeiramente amolecida foi introduzido no canal e forçado apicalmente, sendo mantido por 02 minutos, na seqüência realizou-se a condensação lateral conforme descrito para os subgrupos anteriores.

\subsection{Obturação dos canais das raízes dos grupos G1-3 e G2-3}

Técnica do Thermafil - Foram selecionadas unidades n.․․ $30 \mathrm{com}$ carregadores plásticos envoltos com guta - percha "alphaphase" que foram colocadas no aparelho aquecedor denominado Therma Prep Plus, seguindo orientações do fabricante. O verificador metálico utilizado foi 0 n.. 30 , que acompanha o sistema Thermafil. Foram pinceladas pequenas porções de cimento nas paredes dos canais com auxílio de uma lima do Tipo Kerr n.․ 30 de $21 \mathrm{~mm}$, então, os elementos obturadores com a guta-percha aquecida, foram introduzidos até o degrau apical. Com uma broca esférica de aço em alta rotação o carregador foi seccionado na altura da embocadura do canal radicular. 


\subsection{Obturação dos canais das raízes dos grupos G1-4 e G2-4}

Para realizar esta técnica, o aparelho System B foi ligado e regulado no modo Touch, temperatura $200^{\circ} \mathrm{C}$ e potência 10 , seguindo as recomendações do fabricante. Com auxílio de uma lima do tipo Kerr nำ 30, $21 \mathrm{~mm}$, uma pequena quantidade de cimento foi levada ao interior do canal radicular, procurando-se tocar todas as paredes do mesmo. Um cone de guta - percha FM da Analytic Tecnology com diâmetro inicial compatível a um cone principal 30 foi adaptado e travado no comprimento real de trabalho. Em seguida, a ponta do condensador (tamanho FM) foi colocada no orifício do canal radicular e introduzida em um único e suave movimento, com a ponta permanecendo a $5 \mathrm{~mm}$ aquém do comprimento real de trabalho por um período de 2 segundos. 0 aquecimento foi desativado, mantendo a pressão apical por 10 segundos. Em seguida o condensador foi aquecido por 1 segundo e removido rapidamente do interior do canal. Para o preenchimento dos terços médio e cervical do canal radicular, a temperatura foi mudada para $100^{\circ} \mathrm{C}$. Assentou-se um cone até o limite da obturação do terço apical, introduzindo o mesmo plugger aquecido, condensando verticalmente a guta percha no terço médio do canal e esta seqüência foi repetida até o total preenchimento do canal radicular. Imediatamente após a obturação, para todos os subgrupos, foram realizados os cortes das obturações ao nível cervical e a limpeza com uma bolinha de algodão embebida em álcool. As raízes foram imersas em cera rosa derretida, viabilizando a impermeabilização da área cervical.

Na seqüência os espécimes foram imersos em solução corante de 
Rhodamine $B^{\star}$ a $0,2 \%$ por 72 horas, a $37^{\circ} \mathrm{C}$. Após esse período foram retirados do corante e lavados por 12 horas em água corrente. A seguir foi removida toda a impermeabilização com auxílio de um instrumental cortante e as raízes foram lavadas e escovadas.

Com auxilio de um disco de carburundum, em baixa rotação fez-se um desgaste numa das faces proximais das raízes expondo-se a obturação e a possível marca da infiltração (Figuras 8 a 11).

A

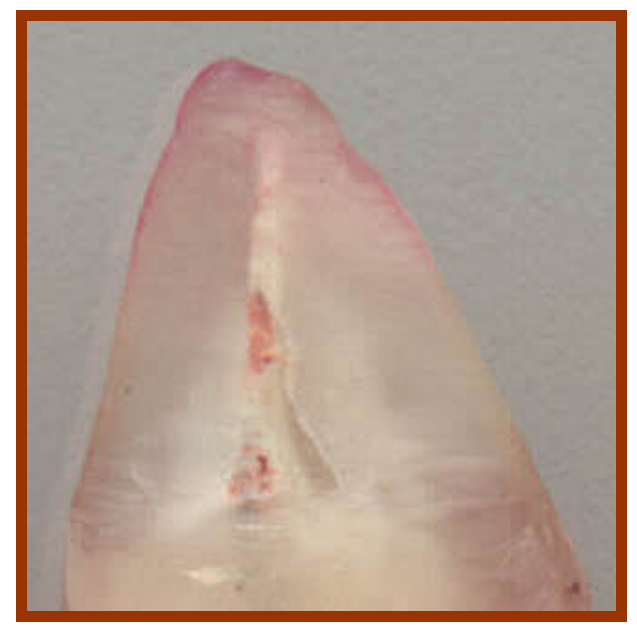

B

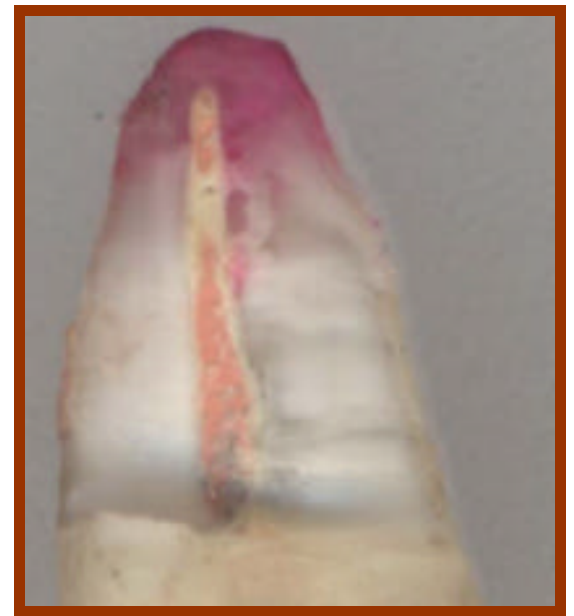

Figura 8 - Hemissecções com canais obturados pela técnica do System B. A - AH Plus com 5\% de hidróxido de cálcio. B - OZE

\footnotetext{
* Departamento de Bioquímica da FOB - USP - Bauru - São Paulo
} 

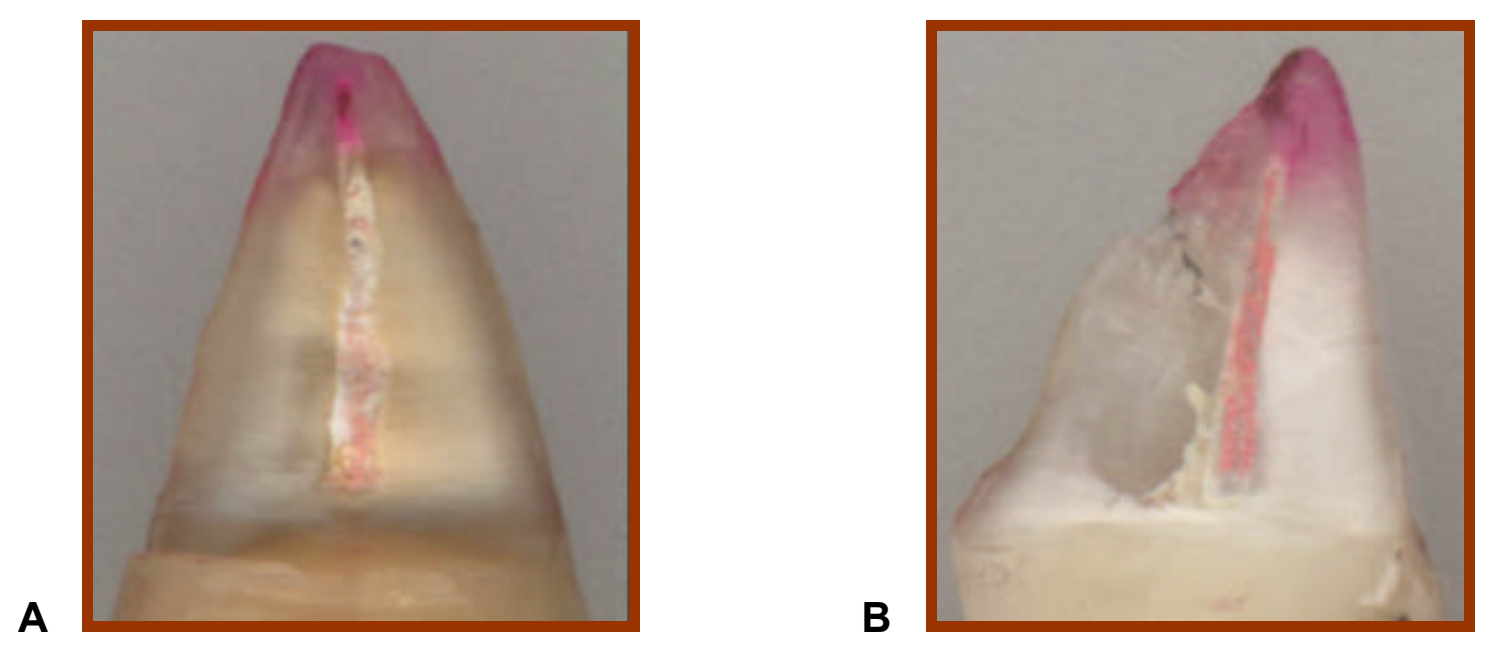

Figura 9 - Hemissecções com canais obturados pela técnica da Condensação Lateral. A - AH Plus com 5\% de hidróxido de cálcio. B - OZE

A

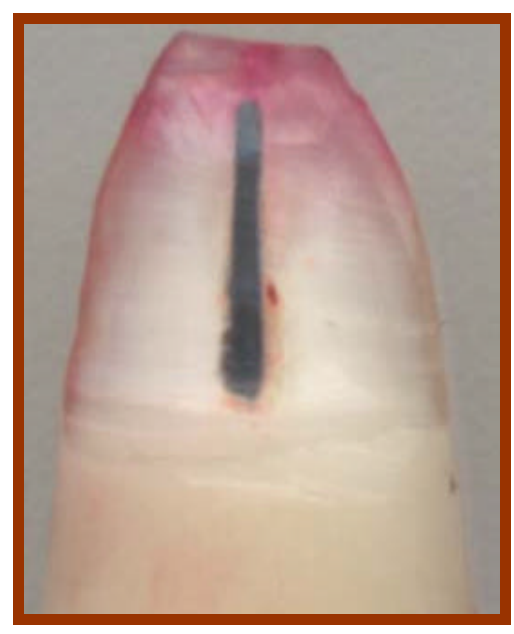

B

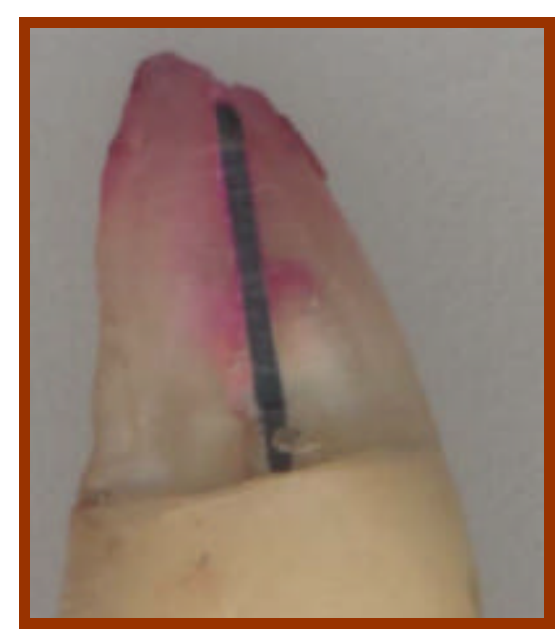

Figura 10 - Hemissecções com canais obturados pela técnica do Thermafil. A - AH Plus com 5\% de hidróxido de cálcio. B - OZE 
A

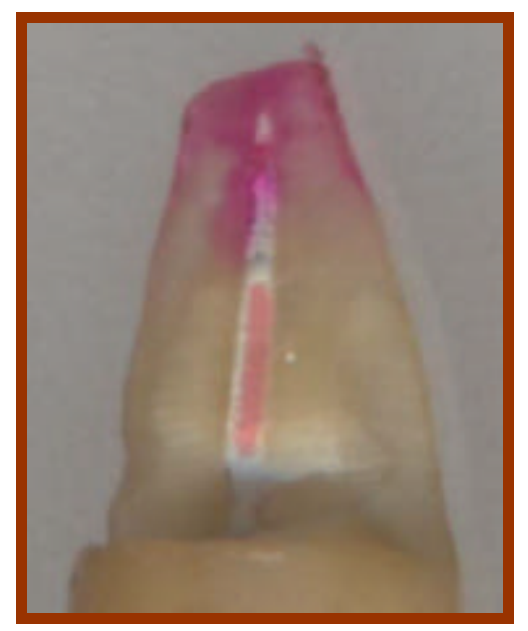

B

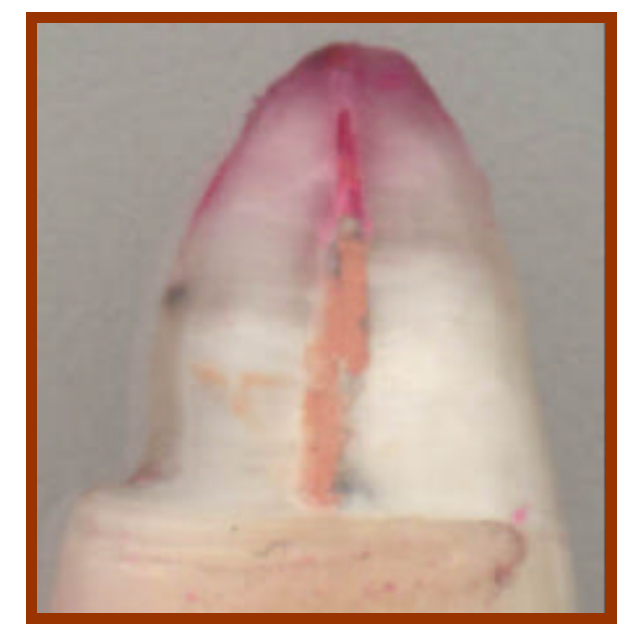

Figura 11 - Hemissecções com canais obturados pela Técnica da Condensação Lateral com Moldagem Térmica do Cone principal. A - AH Plus com $5 \%$ de hidróxido de cálcio. B - OZE

As raízes, assim preparadas, foram dispostas sobre lâminas de vidro e levadas a um microscópio óptico comum, munido de objetiva com aumento de 4x e de uma ocular micrométrica (12X) para a análise da infiltração, pela técnica linear da planimetria, com iluminação direta. Dois observadores fizeram a leitura, atuando independentemente um do outro. Os resultados foram transformados em milímetros, tabulados e submetidos aos cálculos estatísticos pertinentes. 


\section{RESULTADOS}

As médias da infiltração marginal apical de Rhodamine B a 0,2\% verificados as dez raízes de cada sub grupo, estão apresentadas nas tabelas 1 e 2. A tabela 1 apresenta os dados obtidos com o cimento de Óxido de Zinco e Eugenol e a tabela 2, as infiltrações medidas nas obturações realizadas com 0 cimento AH Plus acrescido de 5\% de hidróxido de cálcio. Comparando-se as duas tabelas pode-se verificar a superioridade do cimento $\mathrm{AH}$ Plus acrescido de hidróxido de cálcio (5\% em peso) na capacidade seladora em decorrência da menor infiltração de corante.

Tabela 1 - Infiltrações apicais (em $\mathrm{mm}$ ) de Rhodamine $B$ a $0,2 \%$ medidas nas obturações realizadas com Cimento OZE

CIMENTO OZE

\begin{tabular}{lcccccccccc}
\hline & \multicolumn{10}{c}{ Infiltração } \\
\hline Técnica & $\mathbf{1}$ & $\mathbf{2}$ & $\mathbf{3}$ & $\mathbf{4}$ & $\mathbf{5}$ & $\mathbf{6}$ & $\mathbf{7}$ & $\mathbf{8}$ & $\mathbf{9}$ & $\mathbf{1 0}$ \\
\hline Lateral & 2,92 & 3,9 & 3,41 & 1,46 & 1,7 & 1,95 & 1,7 & 0,48 & 2,68 & 0,48 \\
\hline Moldagem & 0 & 3,3 & 3,3 & 4,14 & 3,41 & 2,07 & 2,92 & 3,9 & 4,14 & 1,34 \\
\hline Thermafil & 3,41 & 4,14 & 3,41 & 1,95 & 1,95 & 3,9 & 3,17 & 1,46 & 1,7 & 3,17 \\
\hline System B & 0 & 3,9 & 1,95 & 0,6 & 0 & 2,68 & 0 & 0 & 1,7 & 1,46 \\
\hline
\end{tabular}

Tabela 2 - Infiltrações apicais (em $\mathrm{mm}$ ) de Rhodamine B a 0,2\% medidas nas obturações realizadas com Cimento AH Plus acrescido de 5\% de hidróxido de cálcio

CIMENTO AH plus

\begin{tabular}{|c|c|c|c|c|c|c|c|c|c|c|}
\hline \multicolumn{11}{|c|}{ Infiltração ( $\mathrm{mm}$ ) } \\
\hline Técnica & 1 & 2 & 3 & 4 & 5 & 6 & 7 & 8 & 9 & 10 \\
\hline Lateral & 0 & 0,36 & 0 & 2,68 & 0,97 & 1,95 & 0 & 0,73 & 1,7 & 0,73 \\
\hline Moldagem & 0,97 & 3,17 & 1,21 & 0,6 & 1,58 & 1,46 & 0,24 & 0,97 & 0 & 3,9 \\
\hline Thermafil & 0 & 1,73 & 3,41 & 0,48 & 3,9 & 3,17 & 1,3 & 1,7 & 0,24 & 4,14 \\
\hline System B & 1,21 & 0 & 0 & 0 & 1,58 & 0 & 0 & 1 & 1,34 & 0,85 \\
\hline
\end{tabular}


Tabela 3 - Médias e desvios padrão das infiltrações medidas nas oitenta obturações realizadas

\begin{tabular}{ccccc}
\hline Cimento & Técnica & $\boldsymbol{X}$ média & $\boldsymbol{d p}$ & dentes \\
\hline OZE & Lateral & 2,068 & 1,152 & 10 \\
\hline OZE & Moldagem & 2,852 & 1,341 & 10 \\
\hline OZE & Thermafil & 2,826 & 0,969 & 10 \\
\hline OZE & System B & 1,229 & 1,352 & 10 \\
\hline AH plus & Lateral & 0,912 & 0,924 & 10 \\
\hline AH plus & Moldagem & 1,411 & 1,236 & 10 \\
\hline AH plus & Thermafil & 2,007 & 1,549 & 10 \\
\hline AH plus & System B & 0,598 & 0,658 & 10 \\
\hline Total & & $\mathbf{1 , 7 3 7}$ & $\mathbf{1 , 3 7 6}$ & $\mathbf{8 0}$ \\
\hline
\end{tabular}

Tabela 4 - Análise da Variância a 2 critérios demonstrando o efeito dos cimentos e das técnicas e também a interação entre ambos

\begin{tabular}{lcccccc}
\hline Efeito & GL efeito & QM efeito & GL erro & $\mathbf{Q M}$ erro & $\boldsymbol{F}$ & $\boldsymbol{P}$ \\
\hline Cimento & 1 & 20,48288 & 72 & 1,389347 & 14,74281 & $0,000262^{*}$ \\
\hline Técnica & 3 & 9,04077 & 72 & 1,389347 & 6,50721 & $0,000587^{*}$ \\
\hline Interação & 3 & 0,64674 & 72 & 1,389347 & 0,4655 & $0,707254 \mathrm{~ns}$ \\
\hline
\end{tabular}

* Diferença estatisticamente significante $(p<0,05)$ (ns) Diferença estatisticamente não significante

Tabela 5 - Teste de Tukey para comparações demonstrando diferença estatisticamente significante favorável á técnica do System B em relação á Moldagem Térmica de cone principal e técnica do Thermafil

\begin{tabular}{lcccc}
\hline Técnica & $\begin{array}{c}\text { Lateral } \\
\mathbf{1 , 4 9}\end{array}$ & $\begin{array}{c}\text { Moldagem } \\
\mathbf{2 , 1 3 1}\end{array}$ & $\begin{array}{c}\text { Thermafil } \\
\mathbf{2 , 4 1 6 5}\end{array}$ & $\begin{array}{c}\text { System } \boldsymbol{B} \\
\mathbf{0 , 9 1 3 5}\end{array}$ \\
\hline Lateral & & 0,321219 & 0,070835 & 0,415546 \\
\hline Moldagem & 0,321219 & & 0,869552 & $0,008967^{*}$ \\
\hline Thermafil & 0,070835 & 0,869552 & & $0,000885^{\star}$ \\
\hline System B & 0,415546 & $0,008967^{\star}$ & $0,000885^{*}$ & \\
\hline
\end{tabular}

* Diferença estatisticamente significante $(p<0,05)$ 

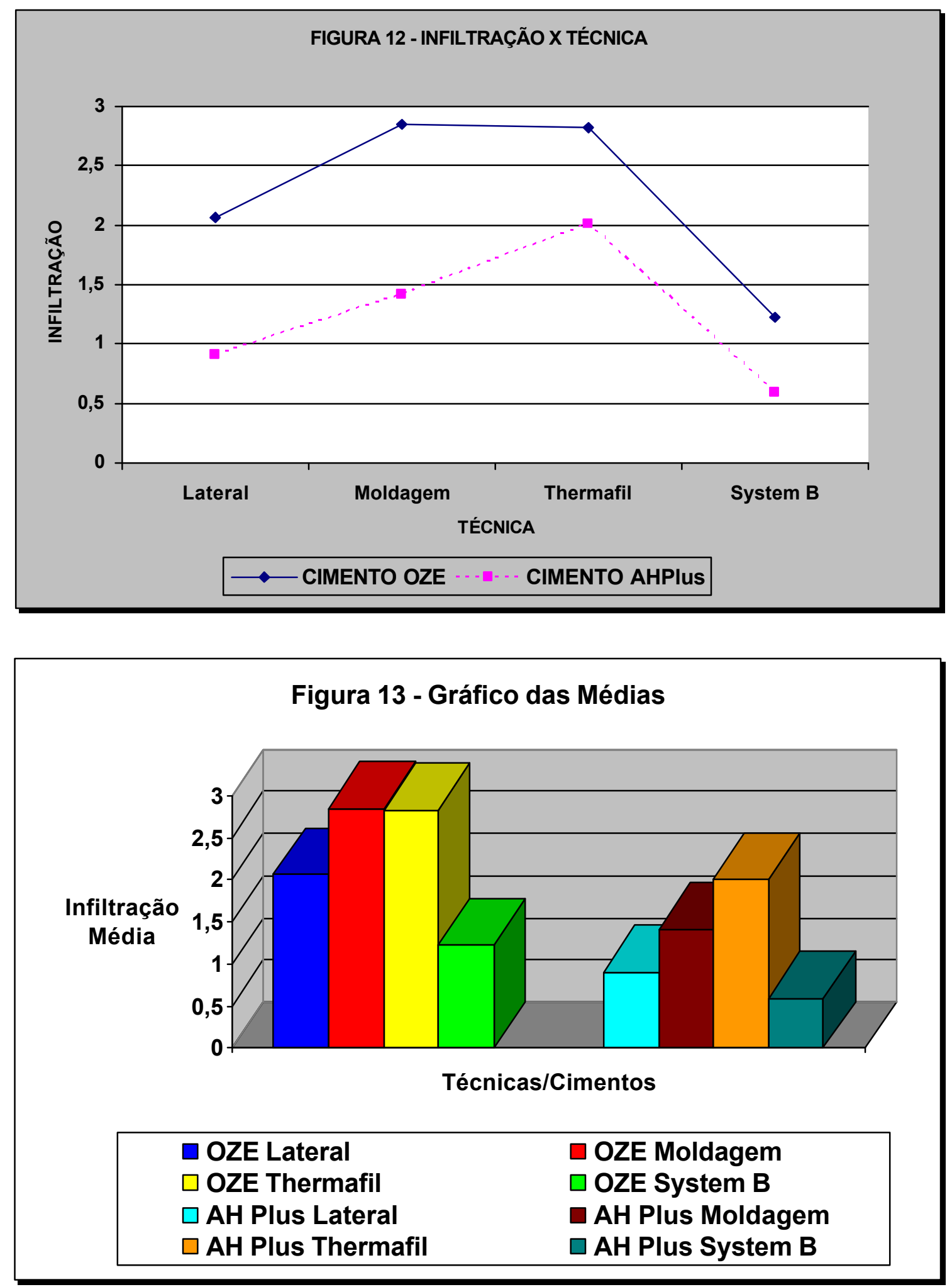

Figuras 12 e 13 - Gráficos representativos das médias de infiltração permitidas pelas obturações em função dos cimentos e técnicas estudadas 


\section{DISCUSSÃO}

\subsection{Da Metodologia}

A História da Endodontia comprova que muitos insucessos nos tratamentos endodônticos devem-se àincompleta obturação do sistema de canais radiculares.

Neste estudo in vitro, avaliou-se o selamento apical propiciado por dois tipos de cimento, o de Óxido de Zinco e Eugenol e o AH Plus acrescido de hidróxido de cálcio e por quatro técnicas obturadoras, a Condensação Lateral, Condensação Lateral com moldagem Térmica direta do cone principal, a técnica do Thermafil e do System B, em canais que sofreram desvio apical de instrumentação, denominado por WEINE ${ }^{89}$ como ZIP. Com relação ao tipo de corpo de prova, a raiz mésio-vestibular de molares superiores humanos foi escolhida por apresentar uma anatomia cujo diâmetro do canal radicular e curvatura dificultam a manutenção da forma original dos canais radiculares durante o preparo biomecânico.

ESTRELA; FIGUEIREDO; PESCE ${ }^{38}$, em 1993, estudando a ocorrência do desvio apical instrumentaram 75 canais curvos pela técnica escalonada, variando-se o instrumento memória nos números 25,30 e 35 . Os resultados evidenciaram o desvio apical (ZIP) em todos os grupos, numa porcentagem de $32 \%, 56 \%$ e $76 \%$ respectivamente, mesmo pré-curvando as limas K-Flex.

Muitos autores descrevem falhas durante o preparo biomecânico de 
canais radiculares curvos com a formação de ZIP apical, dentre eles ALODEH; DOLLER; DUMMER ${ }^{7}$, 1989, ESTRELA ${ }^{37}$, 1990, FIGUEIREDO; MILANO; DUMMER ${ }^{39}, 1991$, LIM; WEBER ${ }^{65}, 1985$, WALTON; TORABINEJAD $^{88}, 1997$.

No presente estudo foram selecionadas oitenta raízes mésiovestibulares de primeiros molares humanos superiores extraídos com anatomia semelhante visto a grande ocorrência de desvios apicais de instrumentação (ZIP) neste grupo dental ${ }^{34,37,88,89}$.

O armazenamento dos dentes em solução aquosa de formol a $10 \%$ objetivou mantê-los hidratados, evitando a putrefação da matéria orgânica (BERNARDINELI ${ }^{12}, 1993$; DAVALOU; GUTMANN; NUNN $\left.{ }^{32}, 1999\right)$.

As coroas foram removidas para facilitar a manipulação dos espécimes durante a pesquisa (DALAT; SPANGBERG $\left.{ }^{30}, 1994\right)$.

Foram confeccionadas bases de acrílico para possibilitar o posicionamento das raízes sempre na mesma posição para tomada radiográfica, bem como a mesma direção dos raios $X$.

A Técnica de instrumentação utilizada foi a Escalonada regressiva

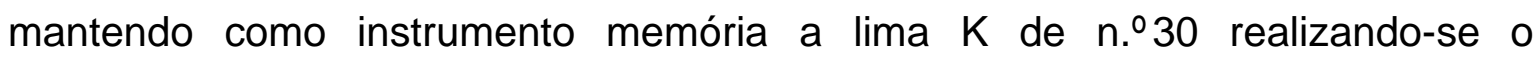

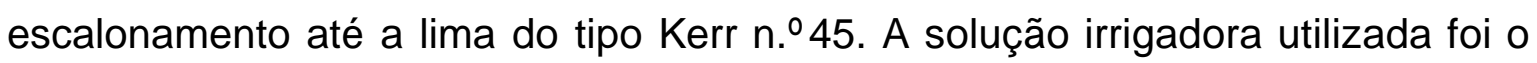
hipoclorito de sódio a 1\% sendo que ao final empregou-se o EDTA para remoção da "smear layer" pois a manutenção desta influe no selamento apical de alguns cimentos. ${ }^{(27,36,41,50,59)}$

A impermeabilização externa, com duas camadas de araldite e uma de esmalte para unhas precedeu a obturação. A Literatura comprova que esses materiais não permitem a infiltração de corante $\left(\right.$ MORAES $^{69}, 1981$ MORAES $^{70}$, 
1984, BERNARDINELI ${ }^{12}, 1993$, TANOMARU FILHO et al. $\left.{ }^{85}, 1999\right)$.

Essa impermeabilização demonstrou ser bastante eficiente não permitindo penetração de marcadores pelos túbulos dentinários e canais acessórios, externamente.

A maioria dos autores que estudaram a qualidade das obturações através da análise da infiltração marginal apical concluiu que o cimento obturador é necessário para aderir a guta-percha na dentina e ajudar a obturar irregularidades, selando o canal radicular por completo (COHEN et al. ${ }^{29}, 1998$, BONETTI FILHO ${ }^{14}, 1986$; JOHNSON; BOND $\left.{ }^{55}, 1999\right)$.

Os cimentos obturadores empregados foram o AH Plus acrescido de Hidróxido de Cálcio e o de Óxido de Zinco e Eugenol.

O cimento foi introduzido ao canal radicular de todos os dentes pela técnica clássica, com a finalidade de padronizar a obturação de todos os grupos.

Na manipulação do cimento de óxido de Zinco e Eugenol, seguiu-se as orientações de MORAES ${ }^{69}$ que recomenda a proporção de $1,8 \mathrm{~g}$ de pó para 1 ml de líquido.

Para a manipulação do cimento AH Plus utilizou-se uma balança de precisão para acrescentar $5 \%$ de hidróxido de cálcio em peso às pastas base e catalisadora.

A escolha do cimento de óxido de zinco e eugenol, deveu-se àsua ampla utilização na odontologia, ainda quanto ao cimento AH Plus, sua escolha deu-se ao fato de ser um cimento à base de resina epóxica e apresentar bons resultados com relação àcapacidade seladora..$^{(5,22,33,95)}$

DUARTE $^{33}$, 1999, em sua tese de doutorado avaliou algumas 
propriedades físico-químicas como radiopacidade, tempo de presa, escoamento, pH, liberação de cálcio e infiltração apical do cimento AH Plus puro e acrescido de Hidróxido de Cálcio (5\% e 10\%) comparado in vitro às do Óxido de Zinco e Eugenol. Concluiu que em relação ao selamento apical o cimento AH Plus puro apresentou infiltração similar ao óxido de zinco e eugenol e quando acrescido de 5 ou $10 \%$ de hidróxido de cálcio houve uma melhora significante no selamento sendo que com a porcentagem menor ele apresentou infiltração ligeiramente menor que com $10 \%$ de hidróxido de cálcio.

No que se refere æ̀ técnicas de obturação estudadas, foram utilizadas a Condensação lateral por ser uma das técnicas mais usadas desde sua idealização por CALLAHAN ${ }^{25}, 1914$. O cimento foi levado ao canal radicular de todos os dentes através da técnica clássica para padronizar a obturação de todos os grupos. Uma variação da Técnica da Condensação Lateral, a moldagem Térmica do cone principal também foi avaliada. Nesta técnica, após a conometria, estando o canal preparado para receber a obturação, plastificou-se a extremidade do cone com instrumental aquecido e imediatamente inseriu-se o cone até o limite apical desejado, sendo pressionado por 2 minutos. Após, prosseguiu-se a técnica da condensação Lateral.

As demais técnicas obturadoras de Termoplastificação: System B e Thermafil despertaram interesse comparativo de eficiência entre elas, pelos resultados encontrados por outros autores e pela facilidade de execução. ${ }^{(13,32,82)}$

Quanto ao método de determinar o selamento apical, o uso de corante como marcador de infiltração tem se mostrado eficiente, de baixo custo, não exigindo equipamentos mais complexos. Dentre os corantes, destacam-se a 
tinta Nankin, Rhodamine B, Azul de metileno, Eosina, Fluoresceína, Violeta de genciana, Nitrato de prata.

O uso de corantes como marcadores de infiltração marginal é um método simples e eficiente. Encontra-se na literatura muitos estudos utilizando o azul de metileno a 2\% (MORAES $^{70}, 1984$, LACOMBE $^{60}$, 1988, DUARTE33, 1999, BERNARDINELI ${ }^{12}, 1993$, TANOMARU FILHO et al. ${ }^{85}, 1999$, YAMASHITA et al. ${ }^{94}, 1999$ ); o azul de metileno a 1\% (TORABINEJAD et al. ${ }^{87}, 1994$, BRANDÃO ${ }^{22}$ 1999, DALÇÓQUIO et al. ${ }^{31}, 2001$ ); nitrato de prata (HOLT; DUMSHA ${ }^{52}$ 2000); Rhodamine B e 0,1\% (CHRISTEN; MITCHELL ${ }^{28}, 1966$ ); Rhodamine B 0,2\% (MORAES $^{69}$, 1981, LEAL et al. ${ }^{62}, 1987$ ); tinta Nankin (AHLBERG; ASSAVANOP; TAY $^{1}$, 1995, ANTONOPOULOS; ATTIN; HELLWIG $\left.{ }^{9}, 1998\right)$.

Foi utilizada, no presente estudo a solução de Rhodamine B na concentração de $0,2 \%$ pH 7,0 (MORAES ${ }^{69}, 1981$ ).

Após a obturação dos canais radiculares, os espécimes foram imediatamente imersos em corante, pois do ponto de vista clínico, a infiltração começa a ocorrer imediatamente após esta etapa.

HAMAOKA $^{46}$, 1995, avaliou a permeabilidade da dentina radicular através da infiltração dos corantes Rhodamine B, azul de metileno e tinta da índia e concluiu que os maiores valores de infiltração foram observados quando do uso do Rhodamine B (40,8\%) seguido pelo Azul de metileno (14,5\%) e a tinta da Índia $(7,5 \%)$.

A utilização do Rhodamine B à $0,2 \%$, neste trabalho, em detrimento ao azul de metileno, amplamente utilizado deveu-se ao fato da utilização do cimento AH Plus acrescido de 5\% de hidróxido de cálcio, procurando assim, evitar 
possíveis resultados falso negativos em razão da ação dos materiais alcalinos sobre o poder de marcação do azul de metileno, o qual pode sofrer descoloração pelo hidróxido de cálcio (WU; KONTAKIOTIS; WESSELINK ${ }^{92}, 1998$ TORABINEJAD; WATSON; PITT FORD ${ }^{86}$ 1993, MORAES et al. $\left.{ }^{71}, 2000\right)$.

SPANGBERG; ACIERNO; CHA $^{83}, 1989$, obtiveram melhores resultados com imersão dos espécimes em ambiente a vácuo. Já, KÜçÜKAY; KÜÇÜKAY; BAYIRLI ${ }^{57}$, 1993, não encontraram diferença estatisticamente significante entre a imersão passiva e àvácuo.

No presente trabalho os espécimes permaneceram imersos, passivamente, em Rhodamine $\mathrm{B}$ a $0,2 \%$ a $37^{\circ} \mathrm{C}$ num período de 72 horas. MORAES $^{70}, 1984$, observou que o tempo pode afetar os resultados pois obteve maiores infiltrações quando os espécimes permaneciam imersos em corante por períodos mais longos.

Após a lavagem dos dentes por 12 horas em água corrente e remoção do material impermeabilizador com instrumento de corte fez-se o desgaste cuidadoso de uma face externa da região apical com disco de carburundum para possibilitar a visualização da interface obturação/parede dentinária sem deslocar ou desgastar o material obturador. Desta forma, por estarem num mesmo plano, dentina, interface e obturação, a leitura da extensão linear do corante através da microscopia óptica ficou facilitada, tomando-se como referência a pigmentação pelo corante na interface material-parede dentinária da porção mais apical até a porção mais coronal ${ }^{(11,21,71)}$.

Para se fazer a leitura da infiltração marginal foi utilizado um microscópio óptico comum munido de uma ocular micrometrada, de execução 
bastante simples e oferecendo resultados confiáveis ${ }^{(11,22,71,85,92)}$. As raízes desgastadas foram dispostas sobre lâminas de vidro e fixadas com cera utilidade. A leitura foi realizada pela técnica de planimetria, utilizando-se uma ocular com aumento de $12,5 \mathrm{X}$ objetiva $4 \mathrm{X}$ e luz direta. A calibragem do microscópio nesta técnica é realizada com auxílio de uma régua micrométrica, a qual possui um círculo, cujo diâmetro corresponde a $1 \mathrm{~mm}$. Este $1 \mathrm{~mm}$, nas condições de ocular micrometrada $12,5 \mathrm{X}$ e objetiva $4 \mathrm{X}$ corresponde a 4,1 divisões da ocular. As medidas foram realizadas a partir da ponta do cone principal, caminhando-se em direção cervical. Os números obtidos por cada observador foram anotados em fichas e posteriormente transformados em milímetros. Foram calculadas as médias a partir das medidas encontradas pelos observadores, obtendo-se o resultado da infiltração marginal sendo encaminhados para análise estatística, para conclusão deste estudo.

\subsection{Dos Resultados}

DUARTE $^{33}, 1999$, avaliou a influência do acréscimo de 5\% e 10\% em peso de hidróxido de cálcio ao cimento AH Plus em relação ao seu tempo de presa, radiopacidade, capacidade seladora, escoamento, pH e liberação de íons cálcio. Concluiu que este acréscimo:

a) Não interferiu significantemente no tempo de presa do material;

b) Não acarretou em alterações significantes da radiopacidade do material;

c) Favoreceu uma melhora significante na capacidade seladora, 
sendo que na proporção de $5 \%$, a infiltração foi ligeiramente menor;

d) Tornou o cimento menos fluido, melhorando o escoamento, principalmente na proporção $5 \%$. Já com acréscimo de 10\%, o cimento ficou muito espesso;

e) Propiciou um pH mais alcalino por parte do cimento e uma maior liberação de Cálcio, sendo esse valores maiores na proporção de $10 \%$.

Neste trabalho foram acrescentados $5 \%$ de Hidróxido de Cálcio em peso ao cimento $\mathrm{AH}$ Plus e constatou-se a superioridade estatisticamente significante deste cimento na capacidade seladora em comparação com o cimento de Óxido de Zinco e Eugenol.

A Técnica do Thermafil, dentre as demais estudadas, mostrou ser a mais rápida e fácil de executar, também constatado por SCOTT; VIRE ${ }^{78}, 1992$, FRAJLICH $^{40}, 1998$, MAZOTTI $^{68}, 2000$.

JUHLIN; WALTON; DOVGAN ${ }^{56}, 1993$, estudando a Técnica do Thermafil, concluíram que na maioria dos preparos, o carregador se adaptou nos terços médio e cervical e que no terço apical, havia falhas de guta-percha, fato este observado em nosso estudo onde a Técnica do Thermafil apresentou resultado pouco satisfatório no selamento apical, constatado na tabela 5.

Segundo BONETTI FILHO et al. ${ }^{16}$, 1998, o carregador deve ser introduzido em um único movimento, para o interior do canal radicular até o comprimento determinado. 
MAZOTTI ${ }^{68}, 2000$, estudando a capacidade de preenchimento do sistema de canais radiculares com a Técnica do Thermafil encontrou deficiência de guta-percha nas regiões mais amplas do canal radicular e ausência de gutapercha em algumas regiões fazendo com que o carregador ficasse em contato com a parede do canal radicular.

A Técnica da Condensação Lateral é a mais empregada na Endodontia sendo muito avaliada na comparação da capacidade de selamento de novas técnicas (CANALDA; BERÁSTEGUI; BRAU ${ }^{26}, 1997$ ).

WU; WESSELINK ${ }^{90}$, 1993, fizeram em levantamento de canais radiculares obturados pela técnica da Condensação Lateral em diferentes estudos, e observaram que a infiltração apical média pode variar de 0,12 a $9,25 \mathrm{~mm}$. Existem variáveis que podem influenciar nos resultados como remoção da "smear layer", tipo de corante, técnica de obturação e cimento obturador, dentre outros.

Neste estudo, a Técnica da Condensação Lateral com lima tipo Kerr apresentou bom resultado (BRAMANTE; BERBERT; PICCINO ${ }^{19}$, 1972) com média de infiltração de $1,49 \mathrm{~mm}$, corroborando com os achados de BONETTI FILHO et al. ${ }^{17}, 2000$, PALHARÉS; FAUS ${ }^{73}, 1995$.

O Grupo do System B apresentou a menor média de infiltração apical de corante $(0,91 \mathrm{~mm})$. Este resultado corrobora com os estudos de DAVALOU; GUTMANN; NUNN ${ }^{32}$, 1999, SILVA NETO et al. ${ }^{79}, 2001$, BROSCO ${ }^{24}, 2002$.

KYTRIDOU; GUTMANN; NUNN ${ }^{59}, 1999$, atribuem à técnica do System B, obturações herméticas e tridimensionais com ótima adaptação da gutapercha à paredes do canal radicular e excelente reprodução de irregularidades, 
características que contribuem para um bom selamento apical.

A Técnica da Condensação Lateral com Moldagem Térmica do cone principal apresentou média de Infiltração de 2,13mm. Plastificar a ponta do cone principal, por meio de toque rápido de uma espátula tipo Hollembak aquecida à chama mostrou-se difícil de ser executada em canais curvos concordando com LOPES; SIQUEIRA JUNIOR ${ }^{67}, 1999$, o que talvez não ocorra em canais retos.

RAMOS; BERBERT* encontraram bons resultados utilizando esta técnica, porém em canais retos.

Diante das condições específicas de realização desta pesquisa e dos resultados apresentados, conheceu-se a capacidade seladora apical de cada técnica e cimentos obturadores estudados em dentes que sofreram ZIP. Quanto às técnicas ou aos próprios cimentos, é importante salientar que resultados inferiores não são suficientes para condená-los. Fatores como domínio de técnica, custo, disponibilidade no mercado devem ser considerados.

\section{CONSIDERAÇÕES FINAIS}

A análise dos resultados possibilita se fazer algumas considerações sobre as técnicas obturadoras e os cimentos utilizados acerca da qualidade do selamento apical proporcionado. Não há dúvida de que o desvio apical de instrumentação é um fator predisponente a um pobre selamento, visto que impede o assentamento do cone principal de guta-percha em todo o perímetro do canal, deixando espaços vazios entre o cone e as paredes dentinárias.

* RAMOS,A.; BERBERT, A. - Comunicação pessoal 
A técnica da condensação lateral, mesmo não se utilizando do aquecimento da guta-percha o que possibilitaria um melhor ajuste do cone, mostrou bons resultados. Já a moldagem térmica, demonstrou não ser uma boa opção, pois, o amolecimento da extremidade do cone, de diâmetro pequeno, dificultou demasiadamente o seu assentamento, no momento da obturação, em razão da curvatura dos canais. Talvez em canais retos, arrombados, ela possa ser melhor indicada.

A técnica do Thermafil, mesmo utilizando-se da guta-percha tipo alfa, que possui, inclusive, propriedade de adesão, não ofereceu os resultados esperados. Já a técnica do System B foi a que proporcionou os melhores resultados, concordando com a maioria dos trabalhos que testaram-na. Sem dúvida, sendo uma técnica termoplastificadora a sua ação junto ao degrau apical deve ter sido efetiva o que possibilitou um ajuste perfeito do cone de guta-percha e o selamento foi superior às demais técnicas.

Quanto aos cimentos, novamente pode-se comprovar o bom selamento produzido pelos cimentos àbase de resina epóxica, neste caso, o $\mathrm{AH}$ Plus. 
7 CONCLUSÕES 


\section{CONCLUSÕES}

De acordo com a metodologia empregada e os resultados destes estudo, concluiu-se que:

1 - A Técnica do System B apresentou, estatisticamente significante $(p<0,05)$, um selamento apical superior ̀̀ técnicas da Condensação Lateral com Moldagem Térmica do cone principal e Thermafil.

2 - Dentre as técnicas obturadoras a classificação daquela que propiciou, numericamente, o melhor para o pior selamento foi a seguinte:

Onda Contínua de Condensação realizada com o System B;

Condensação Lateral realizada com lima tipo Kerr;

Condensação Lateral com moldagem Térmica do cone principal; Thermafil.

3 - O cimento AH Plus acrescido de 5\% de Hidróxido de Cálcio em peso apresentou, estatisticamente significante $(p<0,05)$, um selamento apical superior ao cimento de Óxido de Zinco e Eugenol $(p<0,05)$. 


\section{REFERÊNCIAS BIBLIOGRÁFICAS*}

1. AHLBERG, K.M.F.; ASSAVANOP, P.; TAY, W.M. A comparison of the apical dye penetration patterns shown by methylene blue and India ink in root-filled teeth. Int. Endod. J., v.28, n.1, p.30-4, jan. 1995.

2. AL-DEWANI, N.; HAYES, S.J.; DUMMER, P.M.H. Comparison of laterally condensed and low-temperature thermoplasticized gutta-percha root fillings. J. Endod., v.26, n.12, p. 733-8, Dec. 2000.

3. ALEXANDER, J.B.; GORDON, T.M. A comparison of the apical seal produced by two calcium hydroxide sealers and a Grossman - type sealer when used with laterallymcondensed gutta-percha. Quintessence Int., v.16, n.9, p.615-71, Sept. 1985.

4. ALLEN, D. E. Hermetic sealing of root canals: value in successful endodontia. Dent. Radiogr. Photogr., v.37, p.85-7, 1964.

\footnotetext{
* Normas recomendadas para uso no âmbito da Universidade de São Paulo, com base no documento "Referências Bibliográficas: exemplos", emanado do Conselho Supervisor do Sistema Integrado de Bibliotecas da USP em reunião de 20 de setembro de 1990.
} 
5. ALMEIDA, W.A. Cimentos obturadores de canais radiculares. Avaliação histológica da resposta dos tecidos apicais e periapicais em dentes de cães, após biopulpectomia. Estudo da infiltração apical. Araraquara, 1997. 190p. Tese (Doutorado). Faculdade de Odontologia de Araraquara, Universidade Estadual Paulista.

6. ALMEIDA, W.A. et al. Evaluation of apical sealing of three endodontic sealers. Int. Endod. J., v. 33, n. 1, p. 25-7, Jan. 2000.

7. ALODEH, M.T.; DOLLER, R. \& DUMMER, P.M.H. Shaping of simulated root canals in resin blocks using the step-back technique with K-Files manipulated in a simple in/out filling motion. Int. Endod. J., v.22, n.3, p.10717, May. 1989.

8. ANIC, I.; MATSUMOTO,K. Comparison of the sealing ability of laser-softened, laterally condensed and low-temperature thermoplasticized gutta-percha. J. Endod., v.21, n. 9 p.464-9,Sept. 1995.

9. ANTONOPOULOS, K.G.; ATTIN, T.; HELLWING, E. Evaluation of the apical seal of root canal fillings with different methods. J. Endod., v.24, n.10, p.655-8, Oct. 1998. 
10.BASSILI, L.O. Infiltração apical em obturações de canais realizadas com dois tipos de cimento após aplicação do laser ND: YAG ou Solução de EDTA nas paredes do canal radicular. Bauru, 2002. 75p. Dissertação (Mestrado) Faculdade de Odontologia de Bauru, Universidade de São Paulo.

11.BAUMGARDNER, K.R.; KRELL, K.V. Ultrasonic condensation of gutta-percha: An "in vitro" dye penetration and scanning electron microscopic study. J. Endod., v. 16, n. 6, p. 253-9, June 1990.

12.BERNARDINELI, N. Obturação retrógrada: Avaliação da adaptação ̀̀ paredes da cavidade e infiltração marginal, em função de materiais obturadores e de agentes de limpeza. Bauru, 1993. 168p. Tese (LivreDocência) - Faculdade de Odontologia de Bauru, Universidade de São Paulo.

13.BLUM, J.Y. et al. Analysis of the endogrammes developed during obturations on extracted teeth using System B. J. Endod. v.27, n.11, p661-5, Nov. 2001. 
14.BONETTI FILHO, I. et al. Avaliação in vitro da capacidade seladora de diferentes técnicas de obturação dos canais radiculares através da infiltração do corante Rhodamine B a 0,2\%. Araraquara, 1986. 67p. Dissertação (Mestrado em Dentística Restauradora) - Faculdade de Odontologia, Universidade Estadual Paulista.

15.BONETTI FILHO, I. et al. Capacidade seladora de novos cimentos obturadores, através da infiltração do corante azul de metileno a $2 \%$. Rev. gaúcha Odont., v. 43, n. 4, p. 221-4, jul./ago. 1995.

16.BONETTI FILHO, I. et al. Obturação dos canais radiculares: Técnicas de Termoplastificação de guta-percha. In: LEONARDO, M.R.; LEAL, J.M. Endodontia: Tratamento de canais radiculares. São Paulo: Panamericana, 1998.

17.BONETTI FILHO, I. et al. Avaliação in vitro da capacidade seladora da técnicas de obturação Microseal através da infiltração apical do corante azul de Metileno a 2\%. Rev. bras. Odont, v.57, n.2, p.80-3, mar./abr. 2000.

18.BOWMAN, C.J.; BAUMGARTNER, J.C. Gutta-percha obturation of lateral grooves and depressions. J. Endod., v.28, n.3, p.220-3, Mar. 2002. 
19.BRAMANTE, C.M.; BERBERT, A.; PICCINO, A.C. Técnica de condensação lateral para obturações de canais radiculares de pequenos diâmetros, com cones de guta-percha. Estomat. Cult., v.6, n.1, p.70-2, jan./jun. 1972.

20.BRAMANTE, A.S.; DUARTE, M.A.H.; BRAMANTE, C.M. Capacidade seladora do apexit, pro canal e set sealer em obturação de canais. Rev. bras. Odont., v.53, n.3, p.5-7, maio/jun. 1996.

21.BRAMANTE, C. M. et al. Estudo comparativo de algumas técnicas de obturação de canais radiculares. Rev. bras. Odont.,v.46, n.5, p.26-35, 1989.

22.BRANDÃO, C.G. Propriedades físico-químicas dos cimentos endodônticos resinosos Sealer 26, e dos experimentais. Sealer plus e M.B.P., comparados às do óxido de zinco e eugenol. Bauru, 1999. 150p. Dissertação (Mestrado) - Faculdade de Odontologia de Bauru, Universidade de São Paulo.

23.BRANDÃO, C.G.; MORAES, I.G.; BRAMANTE, C.M. Capacidade seladora apical de cimentos endodônticos ionoméricos. Rev. FOB, v.9, n.1/2, p.2934, jan./jun. 2001. 
24.BROSCO, V.H. Avaliação “in vitro" do selamento apical dos canais radiculares em função de diferentes técnicas de obturação. Bauru, 2002. 136p. Dissertação (Mestrado) - faculdade de Odontologia de Bauru, Universidade de São Paulo.

25.CALLAHAN, J.R. Rosin solution of the sealing of the dentinal tubuli and as an adjuvant in the filling of root canals. J. Allied. Dent. Soc. v.9, p.53-63, 1914 apud MAZOTI, D. Avaliação comparativa in vitro da capacidade de preenchimento do sistema de canais radiculares de diferentes técnicas de obturação. Araraquara, 2000, 192p. Dissertação (Mestrado). Faculdade Odontologia de Araraquara, Universidade Estadual Paulista.

26. CANALDA, S. C.; BERÁSTEGUI, J. E.; BRAU, A. E. Apical sealing using two thermoplasticized gutta-percha techniques compared with lateral condensation. J. Endod., v.23, n.10, p.636-8, Oct. 1997.

27.CERGNEUX, M. et al. The influence of the smear layer on the sealing ability of canal obturation. Int. Endod. J., v.20, n.5, p.228-32, Sept. 1987.

28.CHRISTEN, A.G.; MITCHELL, D.F. A fluorescent method for demonstrating leakage around dental restorations. J. dent. Res., v.45, n.5, p.1485-92, Oct. 1966. 
29. COHEN, S. et al. The evaluation of apical leakage for three endodontic fill system. Gen. Dent., v.46, p.46, p.618-22, 1998.

30.DALAT, D.M., SPANGBERG, L.S.W. Comparison of apical leakage in root canals obturated with various gutta-percha techniques using a dye vacuum tracing method. J. Endod., v. 20, n.7,p.315-9, July 1994.

31.DALÇÓQUIO, C. et. al. Selamento apical após retrobturações com M.T.A., I.R.M., ionômero de vidro e cianoacrilato. Rev. Ass. paul. cirurg. Dent., v.55, n.3, p.194-8, maio./jun. 2001.

32.DAVALOU, S. GUTMANN, J.L.; NUNN, M.H. Assessment of apical and coronal root canal seals using contemporary endodontic obturation and restorative materials and techniques. Int. Endod. J., v.32, n.5, p.338-96, Sept. 1999.

33.DUARTE, M.A.H. Avaliação de algumas propriedades físico-químicas do cimento AH Plus puro e acrescido de hidróxido de Cálcio. Bauru, 1999. 156p. Tese (Doutorado) - Faculdade de Odontologia de Bauru, Universidade de São Paulo.

34.DUMMER, P.M.H.; ALODEH, M.H.A.; DOLLER, R. Shaping of simulated root canals in resin blocks using files activated by a sonic handpiece. Int. Endod. J., v.22, p.211-25, sep.1989. 
35.DUMMER, P.M.H. et al. A laboratory study of root fillings in teeth obturated by lateral condensation of gutta-percha or Thermafil obturators. Int. Endod. J., v.27, n.1, p.32-8, Jan. 1994.

36.ECONOMIDES, N. et al. Long term evaluation of the influence of smear layer removal on the sealing ability of different sealers. J. Endod., v.25, n.2, p.123-5, Feb.1999.

37.ESTRELA, C. Estudo comparativo do desgaste dentinário na parede distal do canal mésio-vestibular do $1^{\circ}$ molar inferior, produzido por três técnicas de instrumentação. Pelotas, 1990. Dissertação (Mestrado) Faculdade de Odontologia, Universidade Federal de Pelotas.

38.ESTRELA,C; FIGUEIREDO, J.A.P.; PESCE, H.F. Avaliação da ocorrência de desvio apical, tendo como fonte de variação o instrumento memória, quando do emprego da Técnica Escalonada. Rev. bras. Odont.; v.50, n.4, p.3-6, jul./ago. 1993.

39.FIGUEIREDO, J.A.D.; MILANO, N.F.; DUMMER, P.M.H. Análise comparative da formação do ZIP apical em canais curvos e atresiados produzido "in vitro” por duas técnicas de instrumentação. Rev. Fac. Odont. U.F.R.S., v.32, n.2, p.2-5, nov. 1991. 
40.FRAJLICH, S. R. et al. Comparative study of retreatment of Thermafil and lateral condensation endodontic fillings. Int. Endod. J., v.31, p.354-7, 1998.

41.GENÇOGLU, N., SAMANI, S., GUNDAY, M. Dentinal wall adaptation of thermaplasticized gutta-percha in the absence or presence of smear layer: a scanning electron microscopic study. J. Endod., v. 19, n.11, p. 558-62, Nov. 1993.

42.GENÇOGLU, N. et al. Comparison of different gutta-percha root filling techniques: Thermafil, Quick-Fill, System B, and lateral condensation. Oral Surg., v.93, n.3, p.333-6, Mar. 2002.

43.GOldBERG, F., MASSONE, E.J., ARTAZA, L.P. Comparison of the sealing capacity of three endodontic filling techniques. J. Endod, v. 21, n. 1, p. 1-3, Jan. 1995.

44.GROSSMAN, L. I. A study of temporary filling as hermetic sealing agents. J. dent. Res., v.18, n.1/2, p.67-71, Jan./Feb. 1939.

45.HAÏ KEL, Y. et al. Apical microleakage of radiolabeled lysozyme over time in three tecniques of root canal obturation. J. Endod., v. 26, n. 3, p. 148-52, Mar. 2000. 
46. HAMAOKA, L. Avaliação in vitro da permeabilidade dentinária radicular, tendo como fonte de variação três diferentes tipos de corantes. São Paulo, 1995. 41p. Dissertação (Mestrado) - Faculdade de Odontologia, Universidade de São Paulo.

47.HATA, G. et al. Sealing ability of Thermafil with and without sealer. J. Endod. v. 18, n.7, p. 322-6. ,July 1992.

48.HATA, G. et al. Sealing ability of thermoplasticized gutta-percha fill tecniques as assessed by a new method of determining apical leakage. J. Endod., v. 21, n. 4, p. 167-72, Apr. 1995.

49.HOLLAND, R. et al. Sealing properties of some root filling materials evaluated with radioisotope. Aust. dent. J., v.19, n.5, p.322-5, Oct. 1974.

50.HOLLAND, $R$ et al. Influência de alguns procedimentos clínicos na infiltração marginal de obturações realizadas pela técnica da condensação lateral. Rev. paul. Odont., v13, n.4, p.29-38, jul./ago. 1991.

51.HOLLAND, R. et al. Análise do selamento marginal obtido com cimentos à base de hidróxido de cálcio. Rev. Ass. Paul. Cirurg. Dent., v.50, n.1, p.614, jan./fev. 1996. 
52.HOLT, G.M.; DUMSHA, T.C. Leakage of amalgam, composite, and Super EBA, compared with a new retrofill material: bone cement. J. Endod., v.26, n.1, p.29-31, Jan. 2000.

53.INGLE, J.I. Root canal obturation. J. Amer. dent. Ass., v.53, n.1, p.47-55, Oct. 1956.

54.INGLE, J. I.; TAINTOR, J. F. Endodontics. 3. ed. Philadelphia, Lea \& Febiger, 1985.

55.JOHNSON, B.T.; BOND M.S. Leakage associated with sigle or multiple increment backfill with the Obtura II gutta-percha system. J. Endod., v.25, n.9, p.613-4, Sept. 1999.

56.JUHLIN, J.J.; WALTON, R.E., DOVGAN, J.S. Adaptation of Thermafil components to canal walls. J. Endod., v.19, n.3, p.130-5, Mar. 1993.

57.KARAGÖZ - KÜÇÜKAY, I.; KÜCÜKAY, S.; BAYIRLI, G. Factors affecting apical leakage assessement. J. Endod., v.19, n.7, p.362-5, July 1993.

58.KUGA, M.C.; MORAES, I.G. ; BERBERT, A. Capacidade seladora do cimento sealapex puro ou acrescido de iodofórmio. Rev. Odont. USP, v.2, n.3, p.139-42, jul./set. 1988. 
59.KYTRIDOU, V.; GUTMANN, J.L.; NUNN, M.H. Adaptation and sealability of two comtemporary obturation techniques in the absence of the dentinal smear layer. Int. Endod. J., v.32, n.6, p.464-74, Nov. 1999.

60.LACOMBE, J.S. et al. A comparison of the apical seal produced by two thermoplasticizad injectable gutta-percha techniques. J. Endod., v.14, n.9, p.445-50, Sept. 1988.

61.LARES,C. ; ELDEEB, M.E. The sealing ability of the Thermafil obturation technique. J. Endod., v.16, n.10, p.474-9, Oct. 1990.

62.LEAL, J.M. et al. Sealapex, AH26 silver free e Fill canal. Avaliação in vitro do selamento apical através da infiltração do corante Rhodamine B a $2 \%$. Influência do tempo de armazenagem. Rev. bras. Odont., v.44, n.6, p.8-14, nov./dez. 1987.

63.LEE, F.S.; VAN CURA, J.E.; BEGOLE E. A comparison of root surface temperatures using different obturation heat sources. J. Endod., v.24, n.9, p. 617-20, Sept. 1998.

64.LEONARDO, M.R.; LEAL, J.M. Endodontia: tratamento de canais radiculares. 3.ed. São Paulo, Panamericana, 1998. 
65.LIM, K.C.; WEBER, R. The validity of simulated root canals for the investigation of the prepared root canal shape. Int. Endod. J., v.18, n.4, p.240-6, Oct. 1985.

66.LIMKANGWALMONGKOL, S. et al. A comparative study of the apical leakage of four root sealers and laterally condensed gutta-percha. J. Endod., v.17, n.10, p.495-9, Oct. 1991.

67.LOPES, H.P.; SIQUEIRA JUNIOR, J.F. Endodontia: biologia e técnica. Rio de janeiro, Medsi, 1999.

68.MAZOTTI, D. Avaliação comparatica “in vitro" da capacidade de preenchimento do sistem de canais radiculares de diferentes Técnicas de Obturação. Araraquara, 2000. 192p. Dissertação (MESTRADO) Faculdade de Odontologia, Universidade Estadual Paulista.

69.MORAES, I.G. Infiltração marginal nas obturações de canais radiculares em função de agentes irrigadores e cimentos obturadores. Bauru, 1981. 114p. Dissertação (MESTRADO) - Faculdade de Odontologia de Bauru, Universidade de São Paulo. 
70.MORAES, I.G. Propriedades físicas de cimentos epóxicos experimentais para obturação de canais radiculares. Bauru, 1984. 149p. Tese (DOUTORADO) - Faculdade de Odontologia de Bauru, Universidade de São Paulo.

71.MORAES, I.G. et al. Influência do hidróxido de cálcio e do EDTA na marcação da infiltração marginal de azul de metileno em obturações de canais radiculares. Rev. FOB, v.8, n.1/2, p.37-44, jan./jun. 2000.

72.NEGM, M.M. The effect of human blood on sealing ability of root canal sealers: An in vitro study. Oral Surg., v.67, n.4, p.449-52, Apr. 1989.

73.PALHARÉS, A.; FAUS, V. A Comparative study of the sealing ability of two root canal obturation techiques. J. Endod., v.21, n.9, p.449-50, Sept.1995.

74.PATHOMVANICH, S.; EDMUNDS, D.H. The sealing ability of Thermafil obturators assessed by four different microleakage techniques. Int. Endod. J., v. 29, n.5, p. 327-34, Sept. 1996.

75.PITT FORD, T.R. The leakage of root fillings using galss ionomer cement and other materials. Brit. dent. J., v.146, n.1, p.273-8, May. 1979.

76. SAHLI, C.C. et al. The apical seal of root canal sealing cements using a radionuclide detection technique. Int. Endod. J., v. 25, n. 5, p. 250-6, Sept. 1992. 
77.SANTA CECÍLIA, M. Selamento apical propiciado pela técnica Thermafil, em canais retos e curvos, avaliados por duas metodologias destintas. Bauru, 1994. 125p. Dissertação (MESTRADO) - Faculdade de Odontologia de Bauru, Universidade de São Paulo.

78.SCOTT, A.C., VIRE, D.E. An evaluation of the ability of a dentin plug to control extrusion of thermoplasticized gutta-percha. J. Endod. v.18, n.2, p.52-7, Feb. 1992.

79.SILVA NETO, U.X. da et al. Selamento apical com as técnicas de Tagger e System B. Rev. FOB., v.9, n.3/4, p. 145-9, jul./dez. 2001.

80.SILVER, G.K.; LOVE, R.M.; PURTON, D.G. Comparison of two vertical condensation obturation techniques: Touch'n heat modified and System B. Int. Endod. J., v. 32, n. 4, p. 287-95, Aug. 1999.

81.SMITH, M.A.; STEIMAN, H.R. An in vitro evaluation of microleakage of two new and two old root canal sealers. J. Endod., v. 20, n. 1, p. 18-21, Jan. 1994.

82.SMITH, R.S. et al. Effect of varying the depth of heat application on the adaptability of gutta-percha during warm vertical compaction. J. Endod., v. 26, n. 11, p. 668-72, Nov. 2000. 
83.SPANGBERG, L.S.W.; ACIERNO, T.G.; CHA, B.C. Influence of entrapped air on the accuracy of leakage studies dye penetration methods. J. Endod., v.15, n. 11 , p. 548-51, Nov.1989.

84.TANOMARU FILHO, M. et al. Avaliação do selamento apical de dois cimentos obturadores àbase de hidróxido de cálcio. Rev. bras. Odont., v.53, n.3, p.2-4, maio/jun. 1996.

85.TANOMARU FILHO, M. et al. Capacidade seladora do Sealer 26 e AH Plus em obturações retrógradas. Rev. paul. Odont., v.21, n.1, p.34-6, jan./fev. 1999.

86.TORABINEJAD, M.; WATSON, T.F.; PITT FORD, T.R. Sealing ability of a mineral trioxide aggregate when used as a root end filling material. $\mathbf{J}$. Endod., v. 19, n. 12, p.591-5, Dec. 1993.

87.TORABINEJAD, M. et al. Dye leakage of four root end filling materials: effects of blood contamination. J. Endod., v.20, n.4, p.159-63, Apr. 1994.

88.WALtON, R.E.; TORABINEJAD, M. Princípios e prática em Endodontia. 2ed. São Paulo, Santos, 1997.

89.WEINE, F.S.; KELLY, R.; LIO, P.J. The effect of preparation procedure on original canal shape and apical foramen shade. J. Endod., v.1, n. 3, p. 25562, Aug. 1975. 
90.WU, M.K.; WESSELINK, P.R. Endodontic leakage studies reconsidered. Part I. Methodology, application and relevance. Int. Endod. J., v. 26, n. 1, p. 3743, jan. 1993.

91.WU, M.; GEE, A.J.; WESSELINK, P.R. Leakage of AH 26 and Ketac-Endo used with injected warm gutta-percha. J. Endod., v. 23, n. 5, p. 331-4, may 1997.

92.WU, M.K.; KONTAKIOTIS, E.G.; WESSELINK, P.R. Long-term seal provided by some root-end filling materials. J. Endod., v. 24, n. 8, p. 557-60, Aug. 1998.

93.WU, M.K; BING FAN, M.S.; WESSELINK, P.R. Leakage along apical root fillings in curved root canals. Part I: Effects of apical transportation on seal of root fillings. J. Endod., v. 26, n. 4, p. 210-6, Apr.2000.

94.YAMASHITA, J.C. et al. Cimento endodôntico AH Plus como material retroobturador: avaliação da capacidade de selamento apical, in vitro relato de caso clínico. J. bras. Odont. Clin., v. 3, n. 18, p. 70-3, 1999.

95.ZMENER, O. et al. Sealing properties of a new epoxy resin-based root-canal sealer. Int. Endod. J., v. 30, n. 5, p. 332-4, Sept. 1997. 


\section{ABSTRACT}

\section{Apical seal properties by any fillings techniques in curved root canal of suffer apical transportation (ZIP)}

The main purpose of this in vitro study is to test the sealing properties (leakage) of two cements (zinc oxide-eugenol and $\mathrm{AH}$ Plus with $5 \%$ calcium hydroxide) using four different apical sealing techniques: lateral condensation only, lateral condensation with direct gutta percha cone thermal molding, Thermafil and System B. Eighty $(\mathrm{N}=80)$ mesial- vestibular human upper molar roots had instrumentation induced apical ZIP and were treated by stepback instrumentation technique (Reamer: Kerr $\mathrm{n}^{\circ}$. 30-45) followed by apical isolation and root filling. All ten $(\mathrm{N}=10)$ specimens of each experimental group $(\mathrm{N}=8)$ were sectioned at cervical level and immersed in $0,2 \%$ Rhodamine $\mathrm{B}$ solution for 72 hours at $37^{\circ} \mathrm{C}$. Longitudinal cuts were made to verifying leakage using an optical microscope and the linear technique. Statistical analysis showed statistically significant results for the group using cement $\mathrm{AH}$ Plus with 5\% calcium hydroxide and System B Technique. 
APÊNDICE 


\section{Universidade de São Paulo Faculdade de Odontologia de Bauru \\ Al. Dr. Octávio Pinheiro Brisolla, 9-75 - Bauru-SP - CEP 17012-901 - C.P. 73 \\ PABX (0XX14)235-8000 - FAX (0XX14)223-4679 \\ Comitê de Éfica em Pesquisa}

Processo $n^{\circ} 15 / 2002$

Bauru, 22 de novembro de 2002

Senhor Professor,

Informamos que após o envio da documentação pendente, o projeto de pesquisa encaminhado a este Comitê denominado "Selamento apical propiciado por algumas técnicas obturadoras em canais curvos que sofreram desvio apical de instrumentaçāo (ZIP)", de autoria de Sônia de Oliveira Santos Schimpf, que será desenvolvido sob a sua orientaçāo foi APROVADO.

Comunicamos que após o envio do trabalho concluído, este Comitê enviará o parecer final, que será utilizado para a publicaçāo do trabalho.

Atenciosamente,

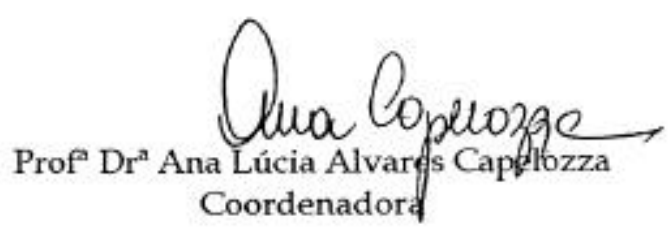

$\mathrm{IIm}^{\circ} \mathrm{Sr}$. Prof. Dr. Ivaldo Gomes de Moraes

DD. Docente do Departamento de Dentística, Endodontia e Materiais Dentários 